\title{
UNIVERSITYOF
}

FORWARD

THINKING

WESTMINSTER用

WestminsterResearch

http://www.westminster.ac.uk/westminsterresearch

Partner selection for reverse logistics centres in green supply chains: a fuzzy artificial immune optimization approach Wu, C. and Barnes, D.

This is an Accepted Manuscript of an article published by Taylor \& Francis in Production Planning and Control, Published online: 12 Aug 2016. The final definitive version is available online: https://dx.doi.org/10.1080/09537287.2016.1221159

(C) Taylor \& Francis Inc.

The WestminsterResearch online digital archive at the University of Westminster aims to make the research output of the University available to a wider audience. Copyright and Moral Rights remain with the authors and/or copyright owners.

Whilst further distribution of specific materials from within this archive is forbidden, you may freely distribute the URL of WestminsterResearch: ((http://westminsterresearch.wmin.ac.uk/).

In case of abuse or copyright appearing without permission e-mail repository@westminster.ac.uk 


\section{Partner selection for reverse logistics centres in green supply chains: a fuzzy artificial immune optimization approach}

Chong $\mathrm{Wu}^{\text {a }}$, David Barnes ${ }^{\mathrm{b}, *}$

${ }^{a}$ School of Management, Xiamen University, Xiamen, 361005 P.R. China

${ }^{b}$ Westminster Business School, University of Westminster, London, NWI 5LS U.K.

Email address of each author:

Chong $\mathrm{Wu}$

Email: Chong.Wu@xmu.edu.cn

Telephone: +86 5922180776

Fax: +865922187289

David Barnes

Email: d.barnes@westminster.ac.uk

Telephone: +44 (0) 2079115000 Extension: 3426

Fax: +44 (0) 2079115703

\footnotetext{
* Corresponding author:
}

David Barnes

Address: Westminster Business School, University of Westminster, London, NW1 5LS U.K.

Telephone: +44 (0) 2079115000 Extension: 3426

Fax: +44 (0) 2079115703

Email: $\underline{\text { d.barnes@westminster.ac.uk }}$ 


\title{
Partner selection for reverse logistics centres in green supply chains: a fuzzy artificial immune optimization approach
}

\begin{abstract}
The design of reverse logistics networks has now emerged as a major issue for manufacturers, not only in developed countries where legislation and societal pressures are strong, but also in developing countries where the adoption of reverse logistics practices may offer a competitive advantage. This paper presents a new model for partner selection for reverse logistic centres in green supply chains. The model offers three advantages. Firstly, it enables economic, environment, and social factors to be considered simultaneously. Secondly, by integrating fuzzy set theory and artificial immune optimization technology, it enables both quantitative and qualitative criteria to be considered simultaneously throughout the whole decision-making process. Thirdly, it extends the flat criteria structure for partner selection evaluation for reverse logistics centres to the more suitable hierarchy structure. The applicability of the model is demonstrated by means of an empirical application based on data from a Chinese electronic equipment and instruments manufacturing company.
\end{abstract}

Keywords: reverse logistics; partner selection; green supply chain; artificial immune optimization; fuzzy set theory

\section{Introduction}

Reverse logistics network design is now a major strategic issue (Govindan et al. 2012). Legislative requirements and societal pressures mean that dumping to landfill is no longer a viable long term solution, both economically and environmentally, to the challenge of disposing of manufactured goods at the end of their useful life (Ferguson and Browne 2001; Eskandarpour et al. 2013). Consequently, many industries now are adopting reverse logistics to comply with government regulations, sustainable development expectations, and to gain competitive advantages from their recovered 
products (Giannetti et al. 2013) in industries as diverse as steel, aircraft, computers, automobiles, chemical, appliances and medical items (Du and Evans 2008; Guarnieri et al. 2015). The practices of leading manufacturing companies such as Xerox, Canon and IBM, have indicated that the recycling and remanufacturing of end-of-life products, or their constituent modules, can have great environmental, economic and social benefits (El Korchi and Millet 2011). The use of such practices requires the establishment of highly efficient reverse logistics networks. Such networks are integral to the operation of a genuinely green supply chain (GSC), and can be used to gain a competitive advantage (Ravi et al. 2005; Chuang and Yang 2014).

Whilst reverse logistics practices have already been used in many applications (photocopiers, cellular telephones, refillable containers, etc.), their operation can be highly costly (Soleimani and Govindan 2014). Symbiotic relationships between the parties involved are necessary as the volume of end-of-life products is probably too small to economically justify individual efforts at end-of-life products reclamation. Thus, the parties involved in the reverse logistics network can reap mutual benefits that arise from working together rather than working independently (Chan 2007; Li et al. 2012). A well-managed reverse logistics network can not only provide important cost savings in procurement, recovery, disposal, inventory holding and transportation, but can also help in customer retention and improved public image for the companies involved (Niknejad and Petrovic 2014).

However, reverse logistics flows can be complex as the end-of-life products being processed can be handled in many different ways (Krumwiede and Sheu 2002). Investment decisions in reverse logistics are both costly and risky for top management as they can impact the financial performance of the company in the long term. Additionally, the operation of the reverse logistics network, like other aspects of the green supply chain, impacts not only its economic performance, but also its environment and social performance. Furthermore, since the emergence of the concept of the triple bottom line (Elkington 1998), the need for firms to achieve high levels of 
performance simultaneously in environmental, economic and social factors has become a major business challenge for firms.

The aim of this paper is to develop a model that will facilitate the construction of an economically, environmentally and socially viable reverse logistics network for the return of end-of-life products for recycling or remanufacturing. Whilst returns can be classified into commercial returns, warranty returns, end-of-life returns, reusable container returns and others (Fleischmann 2001; Lage and Godinho 2012), in this paper, we concentrate on the end-of-life products which have high potential for environmental harm unless appropriately returned. To solve this management problem effectively and efficiently, the proposed model plans to combine fuzzy set theory and artificial immune optimization technique to build a fuzzy artificial immune optimization model.

During its current rapid industrialisation, China is attempting to develop appropriate environmental standards (Dong et al. 2012). Implementing reverse logistics practices as part of sustainable development has the potential to become a competitive advantage for China as its production cost advantages are gradually eroded (Lai et al. 2013). In addition, as a survey of two hundred and nine Chinese manufacturers reveals, institutional pressures have a statistically significant positive influence on top managers' posture towards reverse logistics implementation (Ye et al. 2013). Therefore, in this paper, we apply the proposed model within the Chinese reverse logistics business environment to demonstrate its applicability.

Following this introductory discussion, the paper is structured as follows. Section 2 reviews the current literature on partner selection for reverse logistics centres and reverse logistics network design. Section 3 presents a new fuzzy artificial immune optimization model, which enables us to select the most appropriate partners for reverse logistics centres and construct the reverse logistics network in GSCs. Section 4 demonstrates the applicability of the presented solution approach by means of an empirical application based on a Chinese electronic equipment and instruments 
manufacturing company. And then, in Section 5, a detailed sensitivity analysis is conducted to assess the effect of specified parameters on the final results. Finally, in Section 6, we draw conclusions and outline further research.

\section{Literature review}

Reverse logistics is a relatively new field of study and has attracted little attention from researchers until fairly recently (Min and Ko 2008). As reverse logistics has become increasingly important to those firms seeking to pursue both profitability and sustainability in business strategy (Du and Evans 2008), there has been a boom in reverse logistics management research (Kannan et al. 2012). More recently, Govindan et al. (2015) reviewed three hundred and eighty two papers of reverse logistics and forward/reverse logistics published between 2007 and 2013. They identified the main methods used as either deterministic or stochastic and classified them in accordance with their different attributes: the period (single or multiple), certainty or uncertainty, field of research (reverse logistics or forward/reverse logistics), problem type (qualitative or quantitative), etc. Similar to Atasu and Cetinkaya (2006) and Atasu et al. (2013)'s research findings, Govindan et al. (2015) also pointed out that the application of more comprehensive objectives in the programming problem represented a research gap. In the same year, Agrawal et al. (2015) analyzed two hundred and forty two papers on reverse logistics. They noted that whilst economic factors were usually well-defined and easily usable in the existing models/methods, the use of economic factors alone is not very effective in managing reverse flows of the products.

In order to identify research gaps and opportunities, recent literature on partner selection in reverse logistics in GSCs was reviewed systematically. Keywords, such as reverse logistic, partner selection, and green supply chain, were used to search publications in the leading operations journals in the database of ISI Web of Knowledge from 2000s onwards. 49 papers in high ranked journals were selected for in-depth 
review. We organise this under two broad headings of deterministic and stochastic methods in accordance with Govindan et al. (2015)'s basic classification.

The Venn diagram, Figure 1, can also be used to summarise the overlapping categorisations of existing models/methods of reverse logistics design in the literature created by the three dichotomies: (i) deterministic vs. stochastic, (ii) single vs. multiple periods, and (iii) reverse logistics only vs. both forward and reverse logistics. Under the two broad headings of deterministic and stochastic methods of the following two subsections, more detailed classifications will be used in accordance with these overlapping categorisations shown in Figure 1, e.g. intersection sets $a$ to $f$.

[Take in Figure 1 about here.]

\subsection{Deterministic models/methods for reverse logistics}

Among the existing deterministic models/methods, we can further classify them into three categories in accordance with their different characteristics. The first sub-category are those models/methods which focus on the single period forward/reverse logistics (Intersection set $a$ in Figure 1). Fleischmann et al. (2001) is one of first papers to extend classic facility location models to consider whether to integrate the reverse and forward logistics networks. More recently, Pishvaee et al. (2010) and Ting and Liao (2013) proposed memetic algorithm which uses dynamic search strategy for integrated forward/reverse logistics network design. However, the proposed models neglect the demand uncertainty and the supply of returned products in the multi-product integrated logistics network. Both Das and Chowdhury (2012) and Choudhary et al. (2015) developed quantitative optimization models for forward/reverse logistics. Das and Chowdhury (2012)'s model aims to maximize overall profits while Choudhary et al. (2015)'s model seeking minimize the total carbon-footprint. More importantly, Choudhary et al. (2015)'s model distinguishes between fixed and variable emissions, which is an effective way of measuring and minimising them separately. 
The second sub-category are those models/methods which focus on the multi-period forward/reverse logistics (Intersection set $b$ in Figure 1). In order to consider the problem of optimizing forward and reverse logistics network simultaneously, Ko and Evans (2007) proposed a mixed-integer non-linear programming model for the design of a dynamic distribution network. Their proposed model has the ability to help decision-makers to determine various resource plans, including equipment and human resources. Yet, even though it can solve all of the test problems arising from the complexity of the problem structure, in terms of computation time and a degree of optimality, it still cannot demonstrate that the proposed approach is the optimal one.

The third sub-category are those models/methods which focus on the multi-period reverse logistics (Intersection set $c$ in Figure 1). By applying genetic algorithm, Min et al. (2006), Min and Ko (2008) and Diabat et al. (2013) proposed mixed-integer programming models for the reverse logistics network design. Based on the final results of their computational study, it can be seen that the artificial immune system has advantage over the genetic algorithm in terms of the best fitness value. In addition, only taking cost into account is bound to ignore other important attributes during the decision making process of reverse logistics network design. It is also very important to analyse explicitly the trade-offs among different criteria, such as costs, speed of return, environmental impact, etc.

Alumur et al. (2012) and Schweiger and Sahamie (2013) proposed multi-period optimization models for reverse logistics network design. Both their models are flexible enough to incorporate different reverse network structures. Yet, risk pooling as a feature of uncertainty was not considered by Alumur et al. (2012)'s model. By considering economic, environment and social objectives, Ramos et al. (2014) constructed a multidepot periodic vehicle routing model for a reverse logistics system. Their research is one of the first to take those three objectives into account simultaneously. However, their model addressed each dimension of sustainability individually rather than 
collectively. This may result in shortcomings due to local rather than global optimization.

\subsection{Stochastic models/methods for reverse logistics}

The same as the above classification methodology, among the existing stochastic models/methods, we can further classify them into three categories in accordance with their different characteristics. The first sub-category are those models/methods which focus on the multi-period reverse logistics (Intersection set $d$ in Figure 1). Both Sheu (2008) and Mutha and Pokharel (2009) developed mathematical model for the design of a multiple period reverse logistics network. Sheu (2008) proposed a linear multiobjective optimization model to optimize the operations of both nuclear power generation and the corresponding induced-waste reverse logistics. Yet, the proposed model needs to investigate further the risk estimation measures aiming at different types of nuclear wastes and diverse disintegration phases. In Mutha and Pokharel (2009)'s model, the returned products need to be consolidated in the warehouse before they are sent to reprocessing centres for inspection and dismantling. Their scenario analysis can reflect the different situations on changes in capacities at the processing centres and the quantities of products returned from consumers. Mutha and Pokharel (2009)'s research could be extended by considering variable inventory cost at different facilities.

The second sub-category are those models/methods which focus on the single period reverse logistics (Intersection set $e$ in Figure 1). Lieckens and Vandaele (2007), Srivastava (2008) and Moghaddam (2015) extended existing location-allocation models in the literature. Lieckens and Vandaele (2007)'s model is able to consider which products are time sensitive. Srivastava (2008)'s model can determine the disposition decisions for various grades of different products simultaneously. And in the area of expert and intelligent systems, Moghaddam (2015)'s model developed an algorithm to avoid subjective weighting from decision-makers. Based on the recovery network model proposed by Fleischmann et al. (2001), Salema et al. (2007) developed 
a generalised model for the design of reverse logistics networks. Their research extended the formal recovery network model by developing a capacitated multi-product recovery logistics network model with uncertainty. Yet, the proposed model may face a computational burden as the problem size increases.

Du and Evans (2008) built a bi-objective reverse logistics network optimization model for post-sale service that aims to minimize the overall costs and the total cycle time. It is effective to apply this model when designing reverse logistics networks considering total costs and cycle time simultaneously. Roghanian and Pazhoheshfar (2014) proposed a probabilistic mixed-integer linear programming model for multi-product, multi-stage reverse logistic network design. Very importantly, in considering both structure of network and transportation strategy, their probabilistic model was converted into a deterministic model. This conversion bridges the probabilistic model and the deterministic model for the reverse logistics network design.

The third sub-category are those models/methods which focus on the single period forward/reverse logistics (Intersection set $f$ in Figure 1). Abdallah et al. (2012) introduced an uncapacitated location inventory model for close-loop supply chains. The main strongpoint is the proposed flexible framework for the policymakers. By using carbon credit allocation and trading, the proposed framework can not only enhance the economic feasibility of reverse logistics, but also penalize companies that do not reclaim their environmentally harmful end-of-life products. Ramezani et al. (2013) and Amin and Zhang (2013) present stochastic multi-objective models for forward/reverse logistics network design under an uncertain environment. The uncertainty and multiobjective attributes of the proposed models are good ways to create a more flexibility condition. The results provided by Ramezani et al. (2013)'s model will be useful for decision-makers as the decision-making process considers the financial risk related to the randomness of different parameters. However, as the proposed models designed for single period only, the existing inventory level is not taken into account during the decision making process. 


\subsection{Comparison and summary of literature review}

Table 1 summaries the models/methods in the existing literature discussed above. From Table 1 and the analysis above we can see that, firstly, few of the existing models/methods incorporate qualitative criteria into the decision-making process. However, considering only quantitative criteria, such as the different kinds of direct costs of reverse logistics, may ignore big strategic questions in final decision-making for the partner selection for reverse logistics centres problem. Secondly, a number of different methods have been tried to solve the partner selection for reverse logistics centres problem. However, compared with other existing literature on partner selection in supply chain management, few of them are hybrid models which combine two or more different theories/technologies (Wu and Barnes 2011). Whilst each theory and technology has its own strengths and weaknesses, each may also have its own shortcomings when used to solve particular problems under particular decision-making environments. Thirdly, most of current models/methods consider the criteria/attributes in a flat structure. However, due to the characteristics of multi-criteria decision-making problem, a hierarchy structure with different level criteria will be more suitable. Furthermore, a hierarchy structure is much easier for practitioners to follow and apply.

[Take in Table 1 about here.]

From Figure 1 and Table 1, we can also see that: firstly, more existing models/methods are focused on the single period problem than the multiple-period problem. Secondly, more literature focuses on reverse logistics than forward/reverse logistics. And thirdly, the majority of current models/methods use deterministic decision-making.

In conclusion, from the above literature review we can identify the following research gaps:

(1) There is a need to apply more comprehensive objectives and a broad range of 
decision-making criteria (Atasu and Cetinkaya 2006, Atasu et al. 2013, Govindan et al. 2015). However, it is hard to find existing models/methods that take economic, environment, and social factors into account simultaneously for the partner selection for reverse logistics centres problem in the existing literature (Ramos et al. 2014).

(2) There is further scope to develop hybrid models/methods, in situations where a pure method has shortcomings and does not by itself meet all the decisionmaking requirements. Advanced hybrid models and methods need to capitalise on the different advantages offered from different methods or technologies in combination.

(3) There is a shortage of models/methods which incorporate qualitative evaluation criteria. Without qualitative evaluation criteria decision-making risks ignoring bigger strategic issues.

(4) Current literature makes little use of hierarchy structure in evaluation criteria for partner selection for reverse logistics centres. Rather, it is dominated by the use of the less suitable single criterion or flat criteria structure.

Accordingly, this paper seeks to address these gaps by proposing a new model for partner selection for economically, environmentally and socially viable reverse logistics centres using existing logistics facilities to construct the most appropriate reverse logistics networks in GSCs.

\section{The fuzzy artificial immune optimization model for partner selection for reverse logistics centres in GSCs}

The proposed model combines fuzzy set theory (FST) and artificial immune optimization (AIO) technique to build a fuzzy artificial immune optimization model for partner selection for reverse logistics centres and reverse logistics network construction. The model, firstly, collects and evaluates decision-makers' judgments on qualitative 
criteria by using FST to convert the linguistic variables into quantitative ones. Then, by applying the above quantitative evaluation outputs, the model optimizes the reverse logistics centres selection in GSCs with artificial immune optimization technique.

The use of FST and AIO technique in combination in this way is both novel and potentially highly appropriate. It is novel because there are no other models/methods in the existing reverse logistics and GSC literature which use such an integration of theories/techniques. It is potentially highly appropriate for three reasons. Firstly, the judgments and evaluations of decision-makers are often uncertain and cannot be estimated by any exact number (Bhattacharya et al. 2014). Thus, as the partner selection for reverse logistics centres problem has many uncertainties, focusing only on quantitative information, means that decision-making is bound to have a greater risk of bias. The use of FST enables imprecise and vague judgements and/or information on the potential partners to be more easily defined, collected, and processed ( $\mathrm{Wu}$ and Barnes 2014). This is beneficial as these distinctive characteristics and advantages enable the proposed model to consider the imprecise and vague judgements inherent in environment and social attributes simultaneously rather than deterministic economic attributes alone. Thus, the use of FST gives the model the ability to consider environment and social attributes as well as economic attributes at the same time. Secondly, FST and AIO technique have been widely used and both have their own merits and drawbacks. Integrating FST and AIO technique could overcome the main drawbacks of each approach. On the one hand, as FST does not have a systematic optimization capability, incorporating AIO technique in ways that improve the global optimization ability and efficiency address can overcome this deficiency in FST (Diabat et al. 2013; Lin and Ying 2013). On the other hand, as AIO technique cannot capture or express linguistic variations, incorporating FST in ways that improve the imprecise and vague information processing ability and efficiency can overcome this deficiency in AIO technique (Mezyk and Unold 2011). If FST is integrated with AIO technique, it could leverage the AIO approach to achieve systematic optimization and improve decision-making efficiency by simulating the human immune system (Chan et al. 2013). 
As illustrated in Table 1 and Figure 1, there is, as yet, no literature that combines FST and AIO technique for partner selection for reverse logistics centres problem. The research presented in this paper seeks to address this gap, thereby enhancing the efficiency and effectiveness of partner selection for reverse logistics centres decision making.

The framework proposed for the fuzzy artificial immune optimization approach to partner selection for reverse logistics centres is shown in Figure 2. It comprises three steps, which are now described in more detail.

[Take in Figure 2 about here.]

\subsection{Preparation for decision-making}

This step will identify the potential partners for reverse logistics centres and construct customized criteria which contain the attributes most compatible with the goals of the whole GSC. This is done via the development of an Optimal Hierarchy Criteria, using an adaptation of the criteria construction methodology proposed by $\mathrm{Wu}$ and Barnes (2010). Then, in order to conduct the evaluation, appropriate evaluation data is collected for each potential reverse logistics centre.

\subsection{Fuzzy evaluation information transformation}

Hard accurate data are inappropriate to depict real life conditions under many situations, As human preferences and judgements are often vague in nature, it is very hard to measure individual preferences and judgements using an accurate numerical value. A more realistic method is offered by the use of linguistic assessments rather than exact numerical values (Bhattacharya et al. 2014). Linguistic variables are variables whose values are expressed in linguistic terms (Zimmermann 1991). In the proposed fuzzy artificial immune optimization model, qualitative criteria are evaluated by decisionmakers in the GSC, based on their knowledge and experience, using linguistic variables. 
The fuzzy evaluation information transformation step of the model involves defining, collecting and processing linguistic variables. This step can be divided into the following three sub-steps.

\subsection{1 "If-then rules" building}

In the first sub-step, fuzzy "if-then rules" will be built to relate the customized criteria to compatibility drivers. A fuzzy if-then rule assumes the following form: If $p$ is $M$, then $q$ is $N$, where $M$ and $N$ are the linguistic values which defined by fuzzy sets on the universe of discourse $p$ and $q$, respectively. In general, " $p$ is $M$ " is defined as the premise or antecedent, while " $q$ is $N$ " is defined as the conclusion or consequence.

Expert knowledge, historical data and/or experience of decision-makers are usually used to build the interrelationships between the customized criteria and compatibility drivers in the form of the fuzzy "if-then rules". Table 2 shows a fuzzy "if-then rules" example which will be applied in the empirical application section, such as "if one input is very high and the other is high, then the output is very high".

[Take in Table 2 about here.]

\subsubsection{Linguistic variables fuzzification}

The imprecise and vague nature of the information can be characterized by membership functions. Generic forms of fuzzy numbers include triangular and trapezoidal fully numbers. Both of them can present the imprecise information (Bhattacharya et al. 2014). The intervals with the relevant to the different linguistic variables could overlap to show the existence of inherent fuzziness of adjacent judgement words, for instance low and/or very low (Fammyiwa et al. 2008). The second sub-step applies the simplicity of triangular membership function to measure the degree of membership of each linguistic level relative to the rating scale of 1-100 (shown in Figure 3a and Figure 3b). Figure 3b depicts the fuzzy set definition with five membership or linguistic variable levels 
functions graphically.

[Take in Figure 3 about here.]

\subsubsection{Defuzzification of the fuzzy outputs}

The aim of the third sub-step is to transform the qualitative judgements in the form of linguistic variables into a format that can be used along with quantitative parameters. The output of each rule will be a fuzzy set. However, it is necessary to convert the output of all collection of rules to be a single quantitative value. For this reason, the output fuzzy sets for each rule will first be aggregated into a single output fuzzy set. The final single output fuzzy set can then be defuzzified into a single quantitative value.

In comparison with the largest of $\max \left(\mathrm{Z}_{\mathrm{LOM}}\right)$ and the smallest of $\max \left(\mathrm{Z}_{\mathrm{SOM}}\right)$ defuzzification methods, the centroid of area $\left(\mathrm{Z}_{\mathrm{COA}}\right)$ defuzzification method has the advantage of preventing judgement bias (Famuyiwa et al. 2008). Therefore, it is the most widely used method during the defuzzification processes. Accordingly, this research uses the centroid of area defuzzification method during the defuzzification sub-step. The centroid of area defuzzification can be defined as:

$$
Z_{C O A}=\frac{\int_{Z} \mu_{A}(Z) Z d Z}{\int_{Z} \mu_{A}(Z) d Z}
$$

The different defuzzification methods are shown graphically in Figure 3c. From Figure $3 \mathrm{c}$ we can see that the inputs are accurate numbers limited to the universe of discourse of the input variables. Yet, the output is a fuzzy degree of membership in qualifying linguistic level in the interval between zero and one (Wu and Barnes 2014).

Based on the fuzzy "if-then rules" shown in Table 2, Figure 4 depicts the fuzzy rules reasoning process surface.

[Take in Figure 4 about here.] 


\subsection{Fuzzy artificial immune optimization model construction}

Based on the above two sub-steps, the third sub-step plans to build and apply the fuzzy artificial immune optimization model for partner selection for reverse logistics centres. The model consists of objective function and constraints functions which are discussed in more details as below.

The objective function can be defined as:

$$
\operatorname{Min} \sum_{i=1}^{Q} \sum_{j \in P_{i}}\left(g_{i} \times d_{i j} \times U_{i j}\right)
$$

which $Q=\{1,2, \ldots, q\}$ is the numbers of reverse logistics collection points;

$P=\{1,2, \ldots, p\}$ is the numbers of potential reverse logistics centres;

$P_{i}$ is the set of potential reverse logistics centres which service distance is equal or less than the maximum service capability $D$;

$g_{i}$ is the defuzzification of the fuzzy qualitative evaluation outputs;

$d_{i j}$ is the distance between reverse logistics collection points and the potential reverse logistics centres;

$U_{i j}$ is a $0-1$ variable, if it is 1 , means there is a reclaim connection between reverse logistics collection point $i$ and the potential reverse logistics centre $j$.

The constraints functions are:

$$
\begin{aligned}
& Z_{i j} \leq l_{j}, \quad i \in Q, j \in P_{i} \\
& \sum_{j \in P_{i}} U_{i j}=1, \quad i \in Q \\
& \sum_{j \in P_{i}} l_{j}=n \\
& d_{i j} \leq D \\
& l_{j} \in\{0,1\}, \quad i \in Q, j \in P_{i}
\end{aligned}
$$




$$
Z_{i j} \in\{0,1\}, \quad i \in Q, j \in P_{i}
$$

In the model above, Eq. (1) is the objective function of the artificial immune optimization model to optimize the fuzzy qualitative evaluation of potential reverse logistics centres. Inequality (2) constrains that only reverse logistics centres can collect the products from reverse logistics collection points. Eq. (3) constrains that any reverse logistics collection points can be serviced by one reverse logistics centre only. Eq. (4) constrains the total number of reverse logistics centres. Inequality (5) constrains the maximum service distances between reverse logistics collection points and the potential reverse logistics centre. Eq. (6) and Eq. (7) constrains the values of the variables to be binary.

The optimization model shown above could be solved very efficiently by the AIO algorithm. Figure 5 shows the process of AIO algorithm.

[Take in Figure 5 about here.]

The fuzzy artificial immune optimization model for partner selection for reverse logistics centres can be easily amended, incorporating more, less or different evaluation criteria to suit different decision-making contexts.

\section{An empirical application}

Buring its current rapid industrialisation, China is attempting to develop appropriate environmental standards (Dong et al. 2012). Implementing reverse logistics practices in China as part of sustainable development has the potential to become a competitive advantage as production cost advantages are gradually eroded (Lai et al. 2013). In addition, a survey from two hundred and nine Chinese manufacturers reveals that institutional pressures have a statistically significant positive influence on top managers' posture towards reverse logisties implementation (Ye et al. 2013). In this 
section, the proposed fuzzy artificial immune optimization model for partner selection for reverse logistics centres in GSCs is applied in Company XYY (a pseudonym), which operates in the Chinese Electronic Equipment \& Instruments industry in order to illustrate its practical operability. Company XYY designs and produces power and distribution transformers, electrical drives and motors on the southeast coast of China. The company sees sustainability as a source of competitive advantage, and so it seeks to minimize the environmental impact of its supply chain operations. Consequently, it attempts to ensure its manufacturing as well as its recycle processes are environmentally friendly whilst remaining economically feasible. Furthermore, it strives to design recyclable products, optimize the means of transportation, and make sure its reverse logistics operations are environmentally friendly and economically feasible. At the same time, all of manufacturing and recycle facilities along with its whole supply chain try to comply with international environmental standard ISO 14001.

\subsection{Preparation for decision-making}

Company XYY operates within the whole of mainland China to provide power and distribution transformers, electrical drives and motors for their customers. Because of their products characteristics, the key components of the end-of-life products are not only valuable for recycling, but also environmentally harmful if treated as normal waste materials. Therefore, it is the GSC managers' responsibility is to design and construct an environmental and economic feasible reverse logistics network for end-of-life products. To fulfil this goal, the first task is to select the most appropriate potential partners and identify the reverse logistics centres. After previous market investigation and analysis, Company XYY identifies thirty potential partners and reverse logistics centres around their mainland China market. Most of them are in the main cities of the provinces which the company supplies its products to. The top GSC managers in Company XYY plans to build five reverse logistics centres and construct a reverse logistic network. Table 3 summarises the coordinates of potential partners and reverse logistics centres, whilst Figure 6 shows them graphically. 
[Take in Table 3 and Figure 6 about here.]

After identifying the potential partners and reverse logistics centres, it is necessary to build the customized hierarchy criteria for comprehensive evaluation. During this stage, we adopt the systematic criteria construction methodology proposed by $\mathrm{Wu}$ and Barnes (2010) as the way for the formulating of Optimal Hierarchy Criteria for evaluating the potential reverse logistics centres. The customized hierarchy criteria for partner selection for reverse logistics centres are shown in Table 4.

[Take in Table 4 about here.]

\subsection{Fuzzy evaluation information collection and transformation}

Based on the customized hierarchy criteria, a group of six experts were asked to evaluate the thirty potential partners for reverse logistics centres in linguistic terms (as Figure $3 \mathrm{~b}$ shows). Three of them are supply chain managers in Company XYY. The other three are academic researchers (two from China and one from UK), who all have many years of experience of research in this subject area and knowledge of the Chinese context.

In this research, we adopted the Fuzzy Logic Toolbox, a powerful and user-friendly product of MATH WORKS CO, as our fuzzy reasoning environment, for two reasons. Firstly, the Fuzzy Logic Toolbox has the capability of handling the fuzzy modelling problem in this decision-making situation. Secondly, it is compatible with the artificial immune optimization model which is constructed within the same Matlab environment. Therefore, it is very convenient and much easier for decision-makers to analyse and make decisions by using a single decision-making tool within the same decisionmaking environment. 
The evaluation results are shown in Table 5 in accordance with the customized hierarchy criteria shown in Table 4.

[Take in Table 5 about here.]

Defuzzification of the fuzzy sets is undertaken by applying the fuzzy rules (as shown in Table 2) and the fuzzy rules reasoning processing surface (as shown in Figure 4), proposed in section 3.2. From this we get the defuzzification of the fuzzy qualitative evaluation outputs (shown in Table 6).

[Take in Table 6 about here.]

\subsection{Fuzzy artificial immune optimization model application}

By using the outputs of defuzzification of the fuzzy qualitative evaluation, this sub-step can apply the proposed fuzzy artificial immune optimization model to select and identify the most appropriate partners for reverse logistics centres. Applying the optimization model shown in equation (1) to (7), we get the optimization result shown in Figure 7. The optimization processes are shown in Figure 8.

[Take in Figure 7 and Figure 8 about here.]

From Figure 7, we can see that the optimal solution for the reverse logistics network consists of five sub-networks, each having its own reverse logistics centre: LZ in Northwest China, SJ in North China, CC in Northeast China, HZ in South China, and GY in Southwest China. The optimal solution for reverse logistics network also matches the main market areas of Company XYY. 


\section{Sensitivity analysis}

The purpose of the sensitivity analysis is to examine the effect of specified parameters on the final results (Wu and Barnes 2014). This research increases and decreases the key parameters of the fuzzy artificial immune optimization model, respectively. The results of the sensitivity analysis are discussed in detail below.

(1) At the very beginning, this research applied the fuzzy artificial immune optimization model with different rates of mutation. The optimization processes of best fitness value are shown in Figure 9a. From Figure 9a we can see that, firstly, all of the optimization processes reached the same best fitness value after approximately fifty iterations. This phenomenon gives evidence of the effectiveness of the proposed model in reaching the optimal solution. Secondly, with different rates of mutation, the optimization processes are slightly different. At the start of the optimization phase, the bigger of the rate of mutation, the higher the best fitness value is obtained $(P m=0.6>P m=0.4>P m=0.2)$. Yet, during the middle of the optimization process, different rates of mutation generate different optimization performances before reaching the final optimal solution. Buring this phase, the rate of mutation ( $P m=0.2)$ has the quickest rate of optimization improvement. Finally, comparing the speed to reach the optimal solution, the rate of mutation $(P m=0.6)$ has an advantage over the other two $(P m=0.4$ and $P m=0.2)$. In short, there is a trade-off between the improvement rate and the speed to reach the optimal solution when choosing the rate of mutation.

[Take in Figure 9 about here.]

(2) Population size is also a very important parameter in the artificial immune optimization methodology. Figure $9 \mathrm{~b}$ shows the sensitivity analysis results which compare the best fitness value and average fitness value with respect to different population size. There is a very clear trend for both best fitness value and average fitness value while the population size increases. It can be seen that when the 
population size is between 40 and 50, both the best fitness value and average fitness value reach their optimal results.

(3) Appropriate times of generation are very important in the artificial immune optimization methodology. If the times of generation are too low, the optimal solution cannot be reached. On the contrary, if the times of generation are too high, the efficiency of optimization will be affected. The results of the sensitivity analysis with respect of different times of generation are shown in Figure 9c. From this we can see that the best fitness value and average fitness value are both decreasing while the times of generation are increasing. However, the best fitness value reaches its optimal solution after the times of generation increase to 70 . It will be much easier for us to choose the most appropriate times of generation after doing this sensitivity analysis.

(4) It is a parameter that allows you to adjust the behaviour of the artificial immune optimization methodology. The higher the crossover probability, the fewer individuals continue in the next generation unchanged. It ranges from zero to one. Figure 9d shows the results of a sensitivity analysis with respect of different probabilities of crossover (i.e. the probability that crossover will occur). By increasing the probabilities of crossover, there is a common trend for both best fitness value and average fitness value. Both of them decrease at first, and then, after reaching the optimal solution, both increase rapidly. Therefore, it is necessary to compare the different performances of the proposed model with respect to different probabilities of crossover if we want to improve its effectiveness and efficacy.

(5) This research varies the number of reverse logistics centres to see impact on the different performances of the proposed fuzzy artificial immune optimization model (shown in Figure 10a and 10b). On the one hand, this shows that the proposed model is flexible enough to meet and solve the different decision-making environments and goals. On the other hand, it shows that when the number of reverse logistics 
centres is increased, both of the best fitness value and average fitness value are decrease. This phenomenon can be explained in that the greater the number of reverse logistics centres, the fewer transportation activities needed across the "different" reverse logistics sub-networks. Therefore, the fitness value will be improved. The different types of network will be discussed in more details in the following sensitivity analysis (6).

[Take in Figure 10 about here.]

(6) The different optimal reverse logistics networks with respect of different numbers of reverse logistics centres are shown in Figure 10b. The numbers of reverse logistics centres range from two to seven. For instance, when the number of reverse logistics centres is centralized to only two, CQ and HF are selected as the reverse logistics centres of the GSC. These then serve the east and west sub-networks for reverse logistics respectively. Furthermore, if the number of reverse logistics eentres is expanded to three, $\mathrm{CD}, \mathrm{TJ}$ and $\mathrm{NC}$ are selected as the reverse logisties eentres of the GSC. Therefore, three sub-networks, say west, northeast and southeast, will be built as three centres for the reverse logistics network. As the numbers of reverse logistics centres are expanded, the numbers of sub-networks increase while the original sub-networks breakdown into two or three smaller subnetworks. For example, comparing $N=6$ with $N=7$, only the northwest subnetwork has been broken down into another two smaller sub-networks.

These sensitivity analyses also show some of the business challenges of inventory control and end-of-life products recycle processing, particularly the trade-offs between centralized and decentralized reverse logistics centres/networks. For instance, if Company XYY considers consolidating its reverse logistics operations into fewer locations, say only two as Figure 10b shows, the company should weigh how this decision would affect its operational risks. By putting all of its reverse logistics operations eggs in fewer reverse logistics centres basket, Company XYY would be in a difficult position if there were disruption, such as severe weather or 
a fire. On the other hand, if Company XYY decentralized its reverse logistics networks, it would lose the benefits which come from economies of scale and the smoothing of customer demand variation obtainable from consolidation via centralization.

(7) The sensitivity analysis compares the results of the proposed method using different criteria sets. The left hand of Figure 11 shows the reverse logistic network constructed by optimising economic, environment and social criteria simultaneously. The right hand of Figure 11 shows the reverse logistic network constructed by optimising only economic criteria. The difference between these two arises from the view of competitiveness taken by decision-makers. Taking a view of competitiveness that is based only on economic criteria produces one design of reverse logistic network, whilst a more comprehensive view of competitiveness that includes environmental and social criteria along with economic criteria produces another design. Thus, the proposed model is able to help decision-makers obtain the optimal result using this more comprehensive view of competitiveness, effectively and efficiently.

[Take in Figure 11 about here.]

(8) Finally, it is also interesting to show the difference made to the results by the use of FST. In the proposed model FST uses linguistic variables to measure the individual's preferences and judgements, which are often vague in nature. Without the use of FST, the qualitative criteria (e.g. some environment and social criteria) cannot be evaluated by decision-makers. Therefore, in this sensitive analysis, we use illustrative data to show the optimal results if FST were not employed. The results are shown in Figure 12. From this, we can see that there are big differences between the results. These differences indicate that the use of FST is an important and necessary part in the proposed model.

[Take in Figure 12 about here.] 
In summary, from the analyses (1) to (8) above and Figure 9 to Figure 12, we can conclude that the model proposed in this research can improve the effectiveness and efficiency of partner selection for reverse logistics centres in GSC. Furthermore, it also helps to provide additional insights and enable managers in GSCs to explore the implications of various decision-making situations.

\section{Conclusions}

This paper presents a new model for partner selection for reverse logistics centres in green supply chains. The design of reverse logistics network has now emerged as a major strategic issue for manufacturers, not only in developed countries where legislation and societal pressures are strong, but also in developing countries, such as China, where the adoption of reverse logistics practices has the potential to become a competitive advantage as production cost advantages are gradually eroded. The first contribution of the proposed model is that it provides a systematic and comprehensive process that enables economic, environment, and social factors to be considered simultaneously in decision-making about partner selection for reverse logistics centres in GSCs. Secondly, the proposed model combines fuzzy set theory and artificial immune optimization technology; the first time that such an approach has been applied to this problem. Use of these methods in combination allows the benefits of each to be realised whilst overcoming their individual limitations. Thirdly, it enables both quantitative and qualitative criteria to be considered during the whole decision-making

process at the same time. Last but not least, this research extends the flat criteria structure for partner selection evaluation of reverse logistics centres to the more suitable hierarchy structure. These contributions represent an advance on other existing methods.

There are a number of potential shortcomings in the proposed model. Firstly, the number of criteria in each category is limited. This is because as the number of criteria increases, the number of fuzzy rules increases more quickly, to the extent that they may 
become out of control if the number of criteria exceeds six. Therefore, there is an economic scale for the number of criteria. Secondly, the method used to combine the assessment of the defuzzification of the fuzzy qualitative evaluation outputs could be more comprehensive. A more sophisticated method is needed in order to identify the most appropriate way of assigning different weights to different criteria and how to aggregate them. Thirdly, the outputs of AIO model belong to Pareto solutions, which require thorough and careful comparisons. However, these are not conducted within the proposed model. The identification of the differences between the Pareto solutions would almost certainly surface some interesting managerial revelations. All these shortcomings require further research work if they are to be addressed.

Additionally, we would also suggest the following issues that require further research. Firstly, the proposed model would benefit from expansion to include the element of uncertainty involved in the partner selection for reverse logistics centres problem. Secondly, the comparisons of artificial immune optimization to other heuristics methods, such as Tabu search, are worth investigating. Thirdly, it is interesting to try to compare the results of the proposed model with results of similar methods based on the same inputs, both quantitatively and qualitatively. Finally, the closed-loop multiechelon reverse logistics network configuration, which considers both direct and indirect, and forward and reverse logistics, could be a very interesting and important subject for the further research.

Word Count (exclude references): 7076

\section{Acknowledgements}

This work was financially supported by 'the National Natural Science Foundation of China' (No. 71202058), 'the Natural Science Foundation of Fujian Province of China' (No. 2012J01305), and 'the Specialized Research Fund for the Doctoral Programme of 
Higher Education' (No. 20110121120028). The authors wish to thank the anonymous reviewers for their valuable recommendations and comments. 


\section{References}

Abdallah, T., Diabat, A., and Simchi-Levi, D. 2012. "Sustainable supply chain design: A closed-loop formulation and sensitivity analysis." Production Planning \& Control 23 (2-3): 120-133.

Agrawal, S., Singh, R.K., Murtaza, Q. 2015. "A literature review and perspectives in reverse logistics." Resources Conservation and Recycling 97: 76-92.

Alumur, S.A., Nickel, S., Saldanha-Da-Gama, F., and Verter, V. 2012. "Multi-period reverse logistics network design." European Journal of Operational Research 220 (1): 67-78.

Amin, S.H., and Zhang, G.Q. 2013. "A three-stage model for closed-loop supply chain configuration under uncertainty." International Journal of Production Research 51 (5): 1405-1425.

Atasu, A., and Cetinkaya, S. 2006. "Lot sizing for optimal collection and use of remanufacturable returns over a finite life-cycle." Production and Operations Management 15 (4): 473-487.

Atasu, A., Guide, V.D.R., and Van Wassenhove, L.N. 2008. "Product reuse economics inclosed loop supply chain research." Production and Operations Management $17(5): 483-496$.

Atasu, A., Toktay, L.B., and Van Wassenhove, L.N. 2013. "How collection cost structure drives a manufacturer's reverse channel choice." Production and Operations Management 22 (5): 1089-1102.

Bhattacharya, A., Mohapatra, P., Kumar, V., Dey, P.K., Brady, M., Tiwari, M.K., and Nudurupati, S.S. 2014. "Green supply chain performance measurement using fuzzy ANP-based balanced scorecard: A collaborative decision-making approach." Production Planning \& Control 25 (8): 698-714.

Chan, F.T.S., Prakash, A., and Mishra, N. 2013. "Priority-based scheduling in flexible system using AIS with FLC approach." International Journal of Production Research 51 (16): 4880-4895.

Chan, H.K. 2007. "A pro-active and collaborative approach to reverse logistics - a case study." Production Planning \& Control 18 (4): 350-360.

Choudhary, A., Sarkar, S., Settur, S., Tiwari, M.K. 2015. "A carbon market sensitive optimization model for integrated forward-reverse logistics." International Journal of Production Economics 164: 433-444.

Chuang, S.P., and Yang, C.L. 2014. "Key success factors when implementing a greenmanufacturing system." Production Planning \& Control 25 (11): 923-937.

Das, K., and Chowdhury, A.H. 2012. "Designing a reverse logistics network for optimal collection, recovery and quality-based product-mix planning." International 
Journal of Production Economics 135 (1): 209-221.

Diabat, A., Kannan, D., Kaliyan, M., and Svetinovic, D. 2013. "A optimization model for product returns using genetic algorithms and artificial immune system." Resources, Conservation and Recycling 74: 156- 169.

Dong, X., Li, C., Li, J., Huang, W., Wang, J., and Liao, R. 2012. "Application of a system dynamics approach for assessment of the impact of regulations on cleaner production in the electroplating industry in china." Journal of Cleaner Production 20 (1): 72-81.

Du, F., and Evans, G.W. 2008. "A bi-objective reverse logistics network analysis for post-sale service." Computers \& Operations Research 35 (8): 2617-2634.

Elkington, J. 1998. Cannibals with forks: The triple bottom line of the twenty first century business. London: New Society Publishers.

El Korchi, A., and Millet, D. 2011. "Designing a sustainable reverse logistics channel: The 18 generic structures framework." Journal of Cleaner Production 19 (6-7): 588-597.

Eskandarpour, M., Zegordi, S.H., and Nikbakhsh, E. 2013. "A parallel variable neighborhood search for the multi-objective sustainable post-sales network design problem." International Journal of Production Economics 145 (1): 117131.

Famuyiwa, O., Monplaisir, L., and Nepal, B. 2008. "An integrated fuzzy-goalprogramming-based framework for selecting suppliers in strategic alliance formation." International Journal of Production Economics 113 (2): 862-875.

Ferguson, N., and Browne, J. 2001. "Issues in end-of-life product recovery and reverse logistics." Production Planning \& Control 12 (5): 534-547.

Fleischmann, M., 2001. Quantitative models for reverse logistics: Lecture notes in economics and mathematical systems. Springler-Verlag, Germany.

Fleischmann, M., Beullens, P., Bloemhof-Ruwaard, J.M., and Van Wassenhove, L.N. 2001. "The impact of product recovery on logistics network design." Production and Operations Management 10 (2): 156-173.

Fleischmann, M., Bloemhofruward, J.M., Dekker, R., Vanderlaan, E., Vannunen, J., and Vanwassenhove, L.N. 1997. "Quantitative models for reverse logistics: A review." European Journal of Operational Research 103 (1): 117.

Giannetti, B.F., Bonilla, S.H., and Almeida, C. 2013. "An emergy-based evaluation of a reverse logistics network for steel recycling." Journal of Cleaner Production 46: 48-57.

Govindan, K., Soleimani, H., Kannan, D. 2015. "Reverse logistics and closed-loop supply chain: A comprehensive review to explore the future." European Journal of Operational Research 240 (3): 603-626.

Guarnieri, P., Sobreiro, V.A., Nagano, M.S., Marques Serrano, A.L. 2015. "The 
challenge of selecting and evaluating third-party reverse logistics providers in a multicriteria perspective: A Brazilian case." Journal of Cleaner Production 96: 209-219.

Gonzalez Torre, P.L., and Adenso-Diaz, B. 2006. "Reverse logistics practices in the glass sector in Spain and Belgium." International Business Review 15 (5): 527 546.

Govindan, K., Palaniappan, M., Zhu, Q.H., and Kannan, D. 2012. "Analysis of third party reverse logistics provider using interpretive structural modeling." International Journal of Production Economics 140 (1): 204-211.

Huang, Y.-C., Wu, Y.-C.J., Rahman, S. 2012. "The task environment, resource commitment and reverse logistics performance: Evidence from the Taiwanese high-tech sector." Production Planning \& Control 23 (10-11): 851-863.

Kannan, D., Diabat, A., Alrefaei, M., Govindan, K., and Yong, G. 2012. "A carbon footprint based reverse logistics network design model." Resources Conservation and Recycling 67: 75-79.

Ko, H.J., and Evans, G.W. 2007. "A genetic algorithm-based heuristic for the dynamic integrated forward/reverse logistics network for 3PLS." Computers \& Operations Research 34 (2): 346-366.

Krumwiede, D.W., and Sheu, C. 2002. "A model for reverse logistics entry by thirdparty providers." Omega-International Journal of Management Science 30 (5): 325-333.

Lage, M., and Godinho, M. 2012. "Production planning and control for remanufacturing: Literature review and analysis." Production Planning \& Control 23 (6): 419-435.

Lai, K.H., Wu, S.J., and Wong, C.W.Y. 2013. "Did reverse logistics practices hit the triple bottom line of Chinese manufacturers?" International Journal of Production Economics 146 (1): 106-117.

Li, S., Wang, N., He, Z., Che, A., and Ma, Y. 2012. "Design of a multiobjective reverse logistics network considering the cost and service level." Mathematical Problems in Engineering 2012: 1-21.

Lieckens, K., and Vandaele, N. 2007. "Reverse logistics network design with stochastic lead times." Computers \& Operations Research 34 (2): 395-416.

Lin, S.W., and Ying, K.C. 2013. "Minimizing makespan in a blocking flowshop using a revised artificial immune system algorithm." Omega-International Journal of Management Science 41 (2): 383-389.

Mezyk, E., and Unold, O. 2011. "Mining fuzzy rules using an artificial immune system with fuzzy partition learning." Applied Soft Computing 11 (2): 1965-1974.

Min, H., and Ko, H.J. 2008. "The dynamic design of a reverse logistics network from the perspective of third-party logistics service providers." International Journal 
of Production Economics 113 (1): 176-192.

Min, H., Ko, H.J., and Ko, C.S. 2006. "A genetic algorithm approach to developing the multi-echelon reverse logistics network for product returns." OmegaInternational Journal of Management Science 34 (1): 56-69.

Moghaddam, K.S. 2015. "Fuzzy multi-objective model for supplier selection and order allocation in reverse logistics systems under supply and demand uncertainty." Expert Systems with Applications 42 (15-16): 6237-6254.

Mutha, A., and Pokharel, S. 2009. "Strategic network design for reverse logistics and remanufacturing using new and old product modules." Computers \& Industrial Engineering 56 (1): 334-346.

Niknejad, A., and Petrovic, D. 2014. "Optimisation of integrated reverse logistics networks with different product recovery routes." European Journal of Operational Research 238 (1): 143-154.

Pishvaee, M.S., Farahani, R.Z., and Dullaert, W. 2010. "A memetic algorithm for biobjective integrated forward/reverse logistics network design." Computers \& Operations Research 37 (6): 1100-1112.

Ramezani, M., Bashiri, M., and Tavakkoli-Moghaddam, R. 2013. "A new multiobjective stochastic model for a forward/reverse logistic network design with responsiveness and quality level." Applied Mathematical Modelling 37 (1-2): 328-344.

Ramos, T.R.P., Gomes, M.I., and Barbosa-Povoa, A.P. 2014. "Planning a sustainable reverse logistics system: Balancing costs with environmental and social concerns." Omega-International Journal of Management Science 48: 60-74.

Ravi, V., Shankar, R., and Tiwari, M.K. 2005. "Analyzing alternatives in reverse logistics for end-of-life computers: ANP and balanced scorecard approach." Computers \& Industrial Engineering 48 (2): 327-356.

Roghanian, E., and Pazhoheshfar, P. 2014. "An optimization model for reverse logistics network under stochastic environment by using genetic algorithm." Journal of Manufacturing Systems 33 (3): 348-356.

Salema, M.I., Barbosa-Povoa, A.P., and Novais, A.Q. 2007. "An optimization model for the design of a capacitated multi-product reverse logistics network with uncertainty." European Journal of Operational Research 179 (3): 1063-1077.

Schweiger, K., and Sahamie, R. 2013. "A hybrid Tabu search approach for the design of a paper recycling network." Transportation Research Part E-Logistics and Transportation Review 50: 98-119.

Shaik, M.N., and Abdul-Kader, W. 2013. "Transportation in reverse logistics enterprise: A comprehensive performance measurement methodology." Production Planning \& Control 24 (6): 495-510.

Sheu, J.-B. 2008. "Green supply chain management, reverse logistics and nuclear power 
generation." Transportation Research Part E-Logistics and Transportation Review 44 (1): 19-46.

Soleimani, H., and Govindan, K. 2014. "Reverse logistics network design and planning utilizing conditional value at risk." European Journal of Operational Research 237 (2): 487-497.

Srivastava, S.K. 2008. "Network design for reverse logistics." Omega-International Journal of Management Science 36 (4): 535-548.

Ting, C.K., and Liao, X.L. 2013. "The selective pickup and delivery problem: Formulation and a memetic algorithm." International Journal of Production Economics 141 (1): 199-211.

Wu, C., and Barnes, D. 2010. "Formulating partner selection criteria for agile supply chains: A Dempster-Shafer belief acceptability optimization approach." International Journal of Production Economics 125 (2): 284-293.

Wu, C., and Barnes, D. 2011. "A literature review of decision-making models and approaches for partner selection in agile supply chains." Journal of Purchasing and Supply Management 17 (4): 256-274.

Wu, C., and Barnes, D. 2014. "Partner selection in agile supply chains: A fuzzy intelligent approach." Production Planning \& Control 25 (10): 821-839.

Ye, F., Zhao, X.D., Prahinski, C., and Li, Y.N. 2013. "The impact of institutional pressures, top managers' posture and reverse logistics on performance-evidence from china." International Journal of Production Economics 143 (1): 132-143.

Zimmermann, H.J., 1991. Fuzzy set theory and its applications. Boston: Kluwer Academic Publishers. 


\section{Tables}

Table 1: Proposed model vs. existing approaches in literature of reverse logistics

\begin{tabular}{|c|c|c|c|c|}
\hline $\begin{array}{l}\text { Author(s) \& research } \\
\text { publication years }\end{array}$ & Methods/Models categories & $\begin{array}{l}\text { Structure } \\
\text { of criteria }\end{array}$ & $\begin{array}{l}\text { Types of } \\
\text { criteria }\end{array}$ & Product(s) \\
\hline Min et al. (2006) & Genetic algorithm & Flat & Quantitative & Single \\
\hline Ko \& Evans (2007) & Genetic algorithm & Flat & Quantitative & Multiple \\
\hline $\begin{array}{l}\text { Lieckens \& Vandaele } \\
\text { (2007) }\end{array}$ & $\begin{array}{l}\text { Differential evolution } \\
\text { technique }\end{array}$ & Flat & Quantitative & Single \\
\hline Salema et al. (2007) & Multi-scenario approach & Flat & Quantitative & Multiple \\
\hline Du \& Evans (2008) & Scatter search methodology & Flat & Quantitative & Multiple \\
\hline Srivastava (2008) & $\begin{array}{l}\text { Descriptive modelling \& } \\
\text { optimization techniques }\end{array}$ & Hierarchy & Quantitative & Multiple \\
\hline Sheu (2008) & Multi-objective optimization & Flat & Quantitative & Single \\
\hline Min \& Ko (2008) & Genetic algorithm & Flat & Quantitative & Single \\
\hline $\begin{array}{l}\text { Mutha \& Pokharel } \\
\text { (2009) }\end{array}$ & Mathematical optimization & Flat & Quantitative & Single \\
\hline Pishvaee et al. (2010) & Memetic algorithm & Flat & Quantitative & Single \\
\hline Abdallah et al. (2012) & Mathematical optimization & Flat & Quantitative & Single \\
\hline Alumur et al. (2012) & Mathematical optimization & Flat & Quantitative & Multiple \\
\hline Govindan et al. (2012) & $\begin{array}{l}\text { Interpretive structural } \\
\text { modelling }\end{array}$ & Flat & Quantitative & Single \\
\hline $\begin{array}{l}\text { Das \& Chowdhury } \\
\text { (2012) }\end{array}$ & Mathematical optimization & Single & Quantitative & Multiple \\
\hline Li et al. (2012) & $\begin{array}{l}\text { Non-dominated sorting } \\
\text { genetic algorithm II }\end{array}$ & Flat & Quantitative & Single \\
\hline Amin \& Zhang (2013) & $\varepsilon$-constraint method & Flat & Quantitative & Multiple \\
\hline Diabat et al. (2013) & Genetic algorithm & Flat & Quantitative & Single \\
\hline $\begin{array}{l}\text { Eskandarpour et al. } \\
\text { (2013) }\end{array}$ & $\begin{array}{l}\text { Parallel variable } \\
\text { neighbourhood search }\end{array}$ & Flat & Quantitative & Multiple \\
\hline Giannetti et al. (2013) & Emergy ternary diagram & Single & Quantitative & Single \\
\hline Ramezani et al. (2013) & $\varepsilon$-constraint method & Flat & Quantitative & Multiple \\
\hline Ting \& Liao (2013) & Memetic algorithm & Single & Quantitative & Single \\
\hline $\begin{array}{l}\text { Schweiger \& Sahamie } \\
\text { (2013) }\end{array}$ & Tabu search & Flat & Quantitative & Single \\
\hline $\begin{array}{l}\text { Niknejad \& Petrovic } \\
\text { (2014) }\end{array}$ & Fuzzy optimization & Single & $\begin{array}{l}\text { Quantitative } \\
\text { \& Qualitative }\end{array}$ & Single \\
\hline Ramos et al. (2014) & $\begin{array}{l}\text { Augmented } \varepsilon \text {-constraint } \\
\text { method }\end{array}$ & Flat & Quantitative & Multiple \\
\hline $\begin{array}{l}\text { Roghanian \& } \\
\text { Pazhoheshfar (2014) }\end{array}$ & Genetic algorithm & Flat & Quantitative & Multiple \\
\hline $\begin{array}{l}\text { Soleimani \& Govindan } \\
\text { (2014) }\end{array}$ & Mathematic programming & Flat & Quantitative & Multiple \\
\hline Choudhary et al. (2015) & $\begin{array}{l}\text { Forest data structure } \\
\text { algorithm }\end{array}$ & Flat & Quantitative & Single \\
\hline Guarnieri et al. (2015) & Multicriteria decision aid & Hierarchy & Qualitative & Single \\
\hline Moghaddam (2015) & Goal programming & Flat & Quantitative & Multiple \\
\hline The proposed model & $\begin{array}{l}\text { Fuzzy set and artificial } \\
\text { immune optimization }\end{array}$ & Hierarchy & $\begin{array}{l}\text { Quantitative } \\
\text { \& Qualitative }\end{array}$ & Multiple \\
\hline
\end{tabular}


Table 2: Fuzzy rule base structure for three inputs and one output variables (based on Nepal et al., 2005, Famuyiwa et al., 2008 and Wu and Barnes, 2014)

\begin{tabular}{|c|c|c|c|c|c|c|c|c|}
\hline & & & & Input & & & & Output \\
\hline 1 & Very Low & $\&$ & 1 & Low & $\&$ & 1 & Average & Low \\
\hline 1 & Very Low & $\&$ & 1 & Low & $\&$ & 1 & High & Low \\
\hline 1 & Very Low & $\&$ & 1 & Low & $\&$ & 1 & Very High & Low \\
\hline 1 & Very Low & $\&$ & 1 & Average & $\&$ & 1 & High & Average \\
\hline 1 & Very Low & $\&$ & 1 & Average & $\&$ & 1 & Very High & Average \\
\hline 1 & Very Low & $\&$ & 1 & High & $\&$ & 1 & Very High & Average \\
\hline 1 & Low & $\&$ & 1 & Average & $\&$ & 1 & High & Average \\
\hline 1 & Low & $\&$ & 1 & Average & $\&$ & 1 & Very High & Average \\
\hline 1 & Low & $\&$ & 1 & High & $\&$ & 1 & Very High & High \\
\hline 1 & Average & $\&$ & 1 & High & $\&$ & 1 & Very High & High \\
\hline 2 & Very High & $\&$ & 1 & Very Low & & & & Average \\
\hline 2 & Very High & $\&$ & 1 & Low & & & & High \\
\hline 2 & Very High & $\&$ & 1 & Average & & & & Very High \\
\hline 2 & Very High & $\&$ & 1 & High & & & & Very High \\
\hline 2 & High & $\&$ & 1 & Very Low & & & & Average \\
\hline 2 & High & $\&$ & 1 & Low & & & & Average \\
\hline 2 & High & $\&$ & 1 & Average & & & & High \\
\hline 2 & High & $\&$ & 1 & Very High & & & & Very High \\
\hline 2 & Average & $\&$ & 1 & Very Low & & & & Low \\
\hline 2 & Average & $\&$ & 1 & Low & & & & Low \\
\hline 2 & Average & $\&$ & 1 & High & & & & Average \\
\hline 2 & Average & $\&$ & 1 & Very High & & & & High \\
\hline 2 & Low & $\&$ & 1 & Very Low & & & & Very Low \\
\hline 2 & Low & $\&$ & 1 & Average & & & & Low \\
\hline 2 & Low & $\&$ & 1 & High & & & & Average \\
\hline 2 & Low & $\&$ & 1 & Very High & & & & Average \\
\hline 2 & Very Low & $\&$ & 1 & Low & & & & Very Low \\
\hline 2 & Very Low & $\&$ & 1 & Average & & & & Low \\
\hline 2 & Very Low & $\&$ & 1 & High & & & & Low \\
\hline 2 & Very Low & $\&$ & 1 & Very High & & & & Low \\
\hline 3 & Very Low & & & & & & & Very Low \\
\hline 3 & Low & & & & & & & Low \\
\hline 3 & Average & & & & & & & Average \\
\hline 3 & High & & & & & & & High \\
\hline 3 & Very High & & & & & & & Very High \\
\hline
\end{tabular}

Total number of rules are 125 
Table 3: The coordinates of potential reverse logistics centres

\begin{tabular}{|c|c|c|c|}
\hline No. & $\begin{array}{l}\text { Potential reverse } \\
\text { logistics centres }\end{array}$ & $\begin{array}{c}\text { Coordinate X } \\
\text { (East Longitude) }\end{array}$ & $\begin{array}{c}\text { Coordinate } \mathbf{Y} \\
\text { (Northern Latitude) }\end{array}$ \\
\hline 1 & HB & 126.63 & 45.75 \\
\hline 2 & $\mathrm{CC}$ & 125.35 & 43.88 \\
\hline 3 & SY & 123.38 & 41.80 \\
\hline 4 & $\mathrm{SH}$ & 121.48 & 31.22 \\
\hline 5 & $\mathrm{HZ}$ & 120.19 & 30.26 \\
\hline 6 & $\mathrm{FZ}$ & 119.30 & 26.08 \\
\hline 7 & NJ & 118.78 & 32.04 \\
\hline 8 & $\mathrm{HF}$ & 117.27 & 31.86 \\
\hline 9 & $\mathrm{TJ}$ & 117.20 & 39.13 \\
\hline 10 & $\mathrm{JN}$ & 117.00 & 36.65 \\
\hline 11 & BJ & 116.46 & 39.92 \\
\hline 12 & $\mathrm{NC}$ & 115.89 & 28.68 \\
\hline 13 & SJ & 114.48 & 38.03 \\
\hline 14 & WH & 114.31 & 30.52 \\
\hline 15 & $\mathrm{ZZ}$ & 113.65 & 34.76 \\
\hline 16 & GZ & 113.23 & 23.16 \\
\hline 17 & $\mathrm{CS}$ & 113.00 & 28.21 \\
\hline 18 & TW & 112.53 & 37.87 \\
\hline 19 & HT & 111.65 & 40.82 \\
\hline 20 & HK & 110.35 & 20.02 \\
\hline 21 & XA & 108.95 & 34.27 \\
\hline 22 & NN & 108.33 & 22.84 \\
\hline 23 & GY & 106.71 & 26.57 \\
\hline 24 & CQ & 106.54 & 29.59 \\
\hline 25 & $\mathrm{YC}$ & 106.27 & 38.47 \\
\hline 26 & $\mathrm{CD}$ & 104.06 & 30.67 \\
\hline 27 & $\mathrm{LZ}$ & 103.73 & 36.03 \\
\hline 28 & $\mathrm{KM}$ & 102.73 & 25.04 \\
\hline 29 & $\mathrm{XN}$ & 101.74 & 36.56 \\
\hline 30 & WL & 87.68 & 43.77 \\
\hline
\end{tabular}


Table 4: The customized criteria for partner selection for reverse logistics centres

\begin{tabular}{|c|c|}
\hline Criteria & Sub-criteria \\
\hline \multirow{8}{*}{$\begin{array}{l}\text { Economic assessment } \\
C_{1}\end{array}$} & Amount of recycling end-of-life products - $C_{11} \quad$ (Ravi et al. 2005; \\
\hline & Min et al. 2006; Salema et al. 2007; Srivastava 2008; Mutha and \\
\hline & Pokharel 2009; Roghanian and Pazhoheshfar 2014) \\
\hline & Operational capacity and control - $C_{12}$ (Min et al. 2006; Srivastava \\
\hline & 2008; Mutha and Pokharel 2009; Soleimani and Govindan 2014) \\
\hline & Costs of collection, transportation and inventory holding - $C_{13}$ \\
\hline & (Ravi et al. 2005; Min et al. 2006; Srivastava 2008; Abdallah et al. \\
\hline & 2012; Niknejad and Petrovic 2014) \\
\hline \multirow{6}{*}{$\begin{array}{l}\text { Environment assessment } \\
C_{2}\end{array}$} & Environmental impacts - $C_{2 l}$ (Krumwiede and Sheu 2002; El Korchi \\
\hline & and Millet 2011; Ramos et al. 2014) \\
\hline & Degree of tightness of local legislation - $C_{22}$ (Ravi et al. 2005; Sheu \\
\hline & 2008) \\
\hline & Environmental expenditures $-C_{23} \quad$ (El Korchi and Millet 2011; \\
\hline & Huang et al., 2012) \\
\hline \multirow{5}{*}{$\begin{array}{l}\text { Social assessment } \\
C_{3}\end{array}$} & Impact of corporate citizenship - $C_{31} \quad$ (Ravi et al. 2005; El Korchi \\
\hline & and Millet 2011; Shaik and Abdul-Kader 2013) \\
\hline & Employee's working condition - $C_{32} \quad$ (Ramos et al. 2014) \\
\hline & Green image and customer satisfaction - $C_{33} \quad$ (Bhattacharya et al. \\
\hline & 2014) \\
\hline
\end{tabular}


Table 5: The fuzzy qualitative evaluation on hierarchy criteria

\begin{tabular}{|c|c|c|c|c|c|c|c|c|c|c|}
\hline \multirow{2}{*}{ No } & \multirow{2}{*}{$\begin{array}{c}\text { Potenti } \\
\text { al } \mathbf{R L} \\
\text { centres }\end{array}$} & \multicolumn{3}{|c|}{ Economic assessment } & \multicolumn{3}{|c|}{ Environment assessment } & \multicolumn{3}{|c|}{ Social assessment } \\
\hline & & $C_{11}$ & $C_{12}$ & $C_{13}$ & $C_{21}$ & $C_{22}$ & $C_{23}$ & $C_{31}$ & $C_{32}$ & $C_{33}$ \\
\hline 1 & HB & High & Very High & Low & Low & Low & Very High & Average & High & High \\
\hline 2 & $\mathrm{CC}$ & Average & Very Low & Very Low & Average & Very High & Low & High & Very High & Very High \\
\hline 3 & SY & Average & Very Low & Low & Very Low & Low & High & Very High & Low & Very Low \\
\hline 4 & SH & Average & Average & Very Low & High & Low & High & Very Low & High & High \\
\hline 5 & $\mathrm{HZ}$ & Low & Low & Very High & High & High & High & Low & High & Very High \\
\hline 6 & $\mathrm{FZ}$ & Average & Average & Very Low & Average & High & Very High & Average & Very High & Very High \\
\hline 7 & $\mathrm{NJ}$ & Average & Very High & Very High & High & Low & High & Average & Very Low & Very Low \\
\hline 8 & $\mathrm{HF}$ & High & High & Very High & High & Average & Very High & Very Low & High & Very High \\
\hline 9 & $\mathrm{TJ}$ & High & Low & Very Low & Low & High & Low & Low & Low & High \\
\hline 10 & $\mathrm{JN}$ & High & Very Low & Low & Very Low & Very Low & Very High & Very Low & Average & Average \\
\hline 11 & BJ & Very High & High & High & Low & Average & High & Low & Average & High \\
\hline 12 & $\mathrm{NC}$ & High & Very High & Very High & Average & High & High & Very Low & Low & High \\
\hline 13 & SJ & Low & Low & High & Low & Low & Very High & Low & Very Low & Very High \\
\hline 14 & WH & Very Low & Average & High & Average & High & Average & High & Average & Average \\
\hline 15 & $\mathrm{ZZ}$ & High & Very Low & Very Low & Average & High & High & Very High & Very High & Low \\
\hline 16 & GZ & Average & Average & Very Low & Average & High & Average & Very High & Very High & High \\
\hline 17 & $\mathrm{CS}$ & Very High & Very Low & Very High & High & Average & Very High & High & Very High & Average \\
\hline 18 & TW & Very Low & Very High & Very High & Average & Very High & High & Average & Very Low & Very High \\
\hline 19 & HT & Low & High & Very High & Very Low & Average & Low & Low & Very Low & High \\
\hline 20 & HK & Low & Very High & Average & High & Very Low & Very Low & Very High & Very Low & Average \\
\hline 21 & $\mathrm{XA}$ & Very High & Average & Very High & High & Very High & Average & Average & Very High & High \\
\hline 22 & $\mathrm{NN}$ & Very Low & Average & High & High & High & Very High & Average & Average & Very Low \\
\hline 23 & GY & Very Low & High & High & Very High & Average & Average & Very High & Average & Average \\
\hline 24 & CQ & Very Low & Low & Average & Very High & Average & Very High & High & Very Low & Very Low \\
\hline 25 & $\mathrm{YC}$ & High & Low & Very Low & Low & Average & High & Very Low & Very Low & Very Low \\
\hline 26 & $\mathrm{CD}$ & Average & Very Low & Very Low & Very High & Low & Very Low & Low & High & Very Low \\
\hline 27 & $\mathrm{LZ}$ & High & Low & Low & Very Low & Very Low & Very Low & High & Very Low & High \\
\hline 28 & KM & Very High & Very High & Very High & Very Low & Average & Low & High & High & High \\
\hline 29 & $\mathrm{XN}$ & High & Very High & Average & Average & Very Low & Very High & High & Average & High \\
\hline 30 & WL & Very High & Low & Average & Very Low & Low & High & Very Low & Average & Very Low \\
\hline
\end{tabular}


Table 6: The defuzzification of the fuzzy qualitative evaluation outputs

\begin{tabular}{|c|c|c|c|c|}
\hline No. & $\begin{array}{c}\text { Potential RL } \\
\text { centres }\end{array}$ & $\begin{array}{c}\text { Economic } \\
\text { criteria }\end{array}$ & $\begin{array}{c}\text { Environment } \\
\text { criteria }\end{array}$ & $\begin{array}{l}\text { Social } \\
\text { criteria }\end{array}$ \\
\hline 1 & $\mathrm{HB}$ & 0.595 & 0.456 & 0.643 \\
\hline 2 & $\mathrm{CC}$ & 0.340 & 0.593 & 0.839 \\
\hline 3 & SY & 0.249 & 0.261 & 0.405 \\
\hline 4 & $\mathrm{SH}$ & 0.236 & 0.459 & 0.518 \\
\hline 5 & $\mathrm{HZ}$ & 0.490 & 0.757 & 0.607 \\
\hline 6 & FZ & 0.334 & 0.696 & 0.835 \\
\hline 7 & NJ & 0.707 & 0.551 & 0.237 \\
\hline 8 & $\mathrm{HF}$ & 0.846 & 0.712 & 0.584 \\
\hline 9 & $\mathrm{TJ}$ & 0.393 & 0.449 & 0.478 \\
\hline 10 & $\mathrm{JN}$ & 0.393 & 0.261 & 0.249 \\
\hline 11 & BJ & 0.744 & 0.416 & 0.394 \\
\hline 12 & $\mathrm{NC}$ & 0.778 & 0.607 & 0.357 \\
\hline 13 & $\mathrm{SJ}$ & 0.407 & 0.454 & 0.357 \\
\hline 14 & WH & 0.393 & 0.592 & 0.445 \\
\hline 15 & $\mathrm{ZZ}$ & 0.261 & 0.619 & 0.670 \\
\hline 16 & GZ & 0.239 & 0.435 & 0.867 \\
\hline 17 & $\mathrm{CS}$ & 0.674 & 0.725 & 0.684 \\
\hline 18 & TW & 0.631 & 0.658 & 0.465 \\
\hline 19 & HT & 0.688 & 0.249 & 0.357 \\
\hline 20 & HK & 0.533 & 0.265 & 0.560 \\
\hline 21 & XA & 0.749 & 0.758 & 0.655 \\
\hline 22 & NN & 0.437 & 0.670 & 0.248 \\
\hline 23 & GY & 0.490 & 0.631 & 0.688 \\
\hline 24 & CQ & 0.287 & 0.774 & 0.326 \\
\hline 25 & $\mathrm{YC}$ & 0.357 & 0.500 & 0.080 \\
\hline 26 & $\mathrm{CD}$ & 0.227 & 0.345 & 0.357 \\
\hline 27 & $\mathrm{LZ}$ & 0.472 & 0.080 & 0.550 \\
\hline 28 & $\mathrm{KM}$ & 0.867 & 0.249 & 0.644 \\
\hline 29 & $\mathrm{XN}$ & 0.690 & 0.488 & 0.599 \\
\hline 30 & WL & 0.576 & 0.381 & 0.236 \\
\hline
\end{tabular}




\section{Figures}

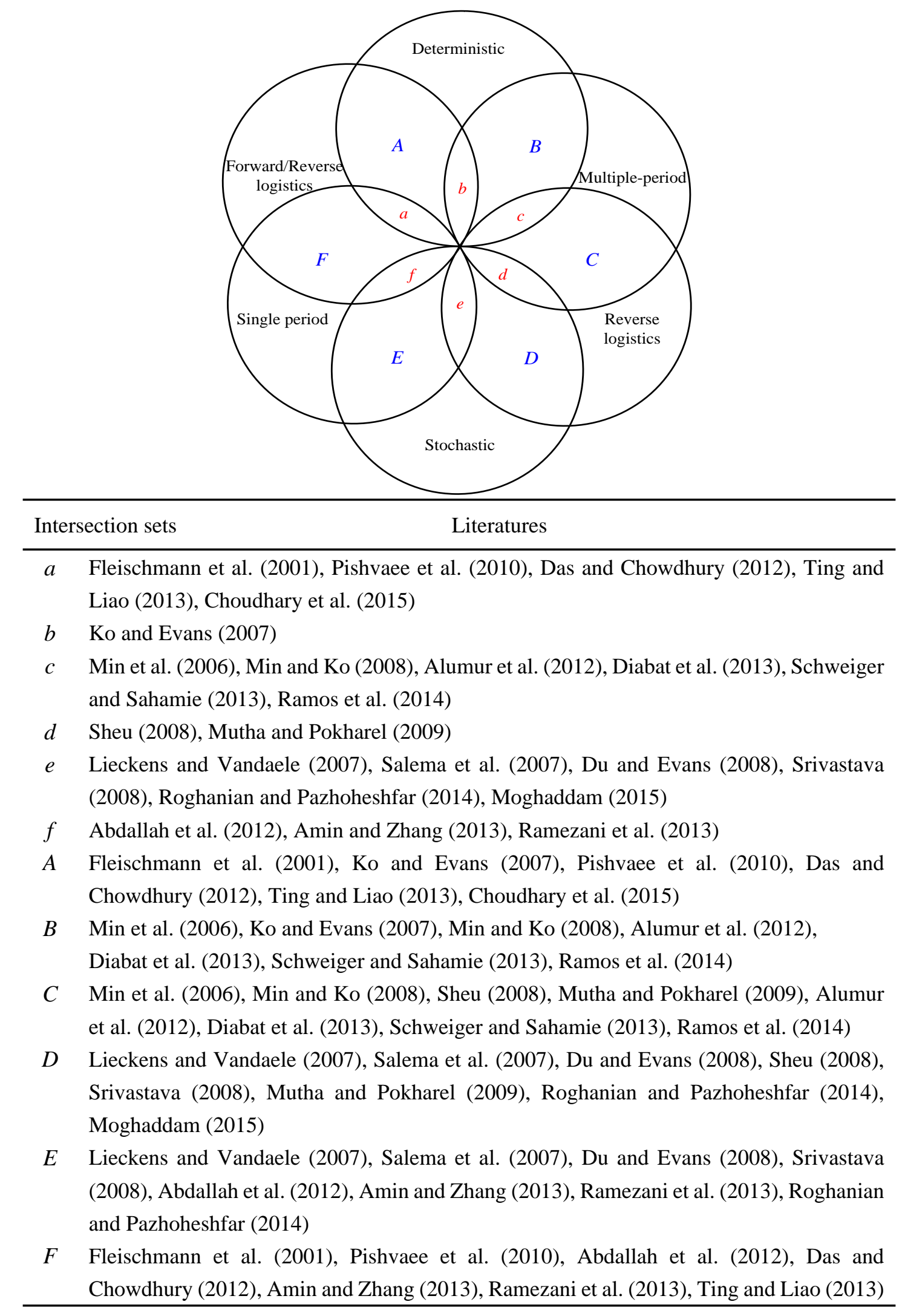

Figure 1: Venn diagram of the classification of existing models/methods 


\section{Step 1: Preparation for decision-making}

( Identify potential partners of reverse logistics centres

( Construct customization criteria by using Optimal Hierarchy Criteria formulation model (Wu and Barnes, 2010)

( Evaluation data collection for each potential RL centres

\section{Step 2: Fuzzy evaluation information transformation}

口 "If-then rules" building

[. Linguistic variables fuzzification

․ Fuzzy rules application

․ Defuzzification of the fuzzy outputs

Step 3: Fuzzy artificial immune optimization model application

( Construction of the fuzzy artificial immune optimization model

( Optimization objectives and parameters definition

4. Application of the fuzzy artificial immune optimization model

(.) Sensitivity analysis

Figure 2: The framework for the fuzzy artificial immune optimization model for partner selection for reverse logistics centres 


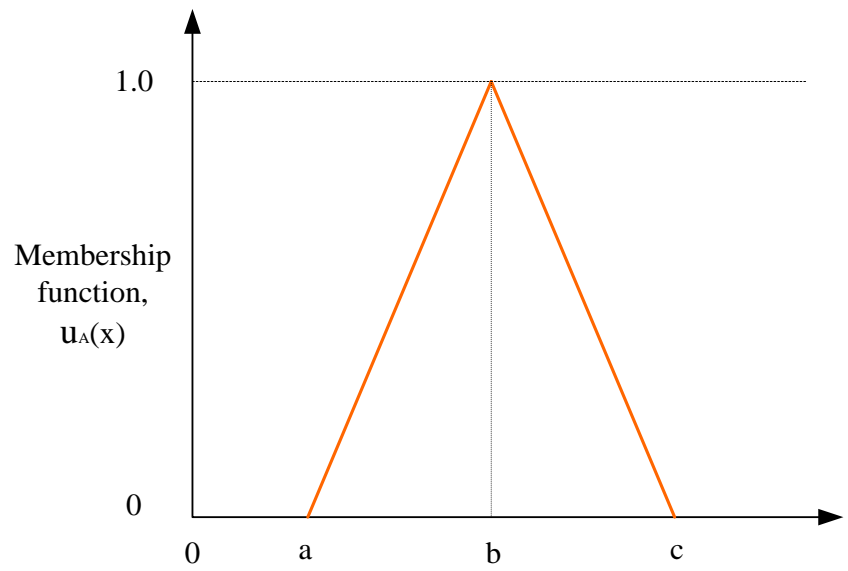

Figure 3a: Generic triangular form of fuzzy numbers

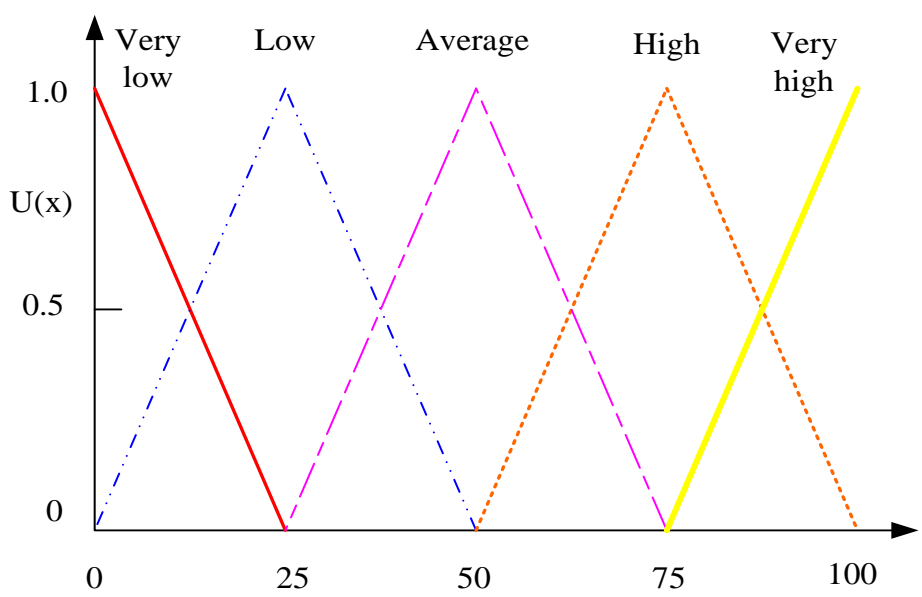

Figure 3b: Membership functions for linguistic variables

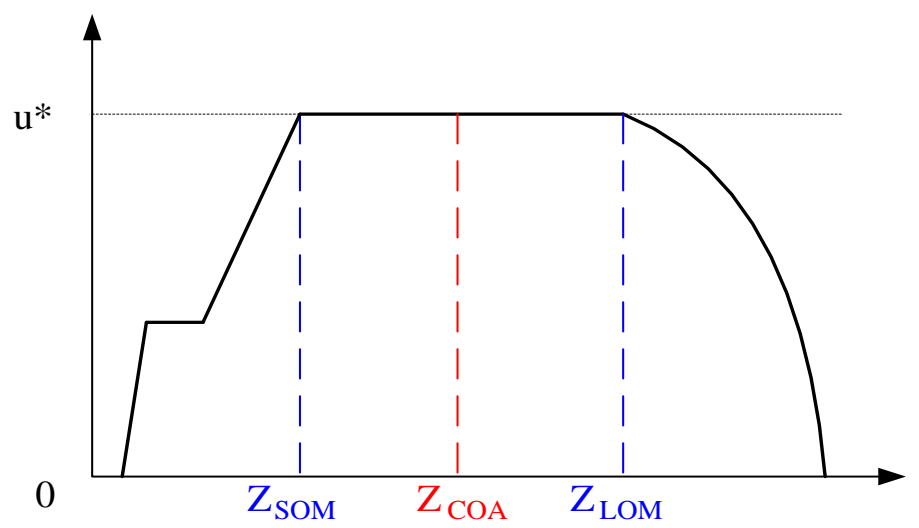

Figure 3c: Various defuzzification schemes 


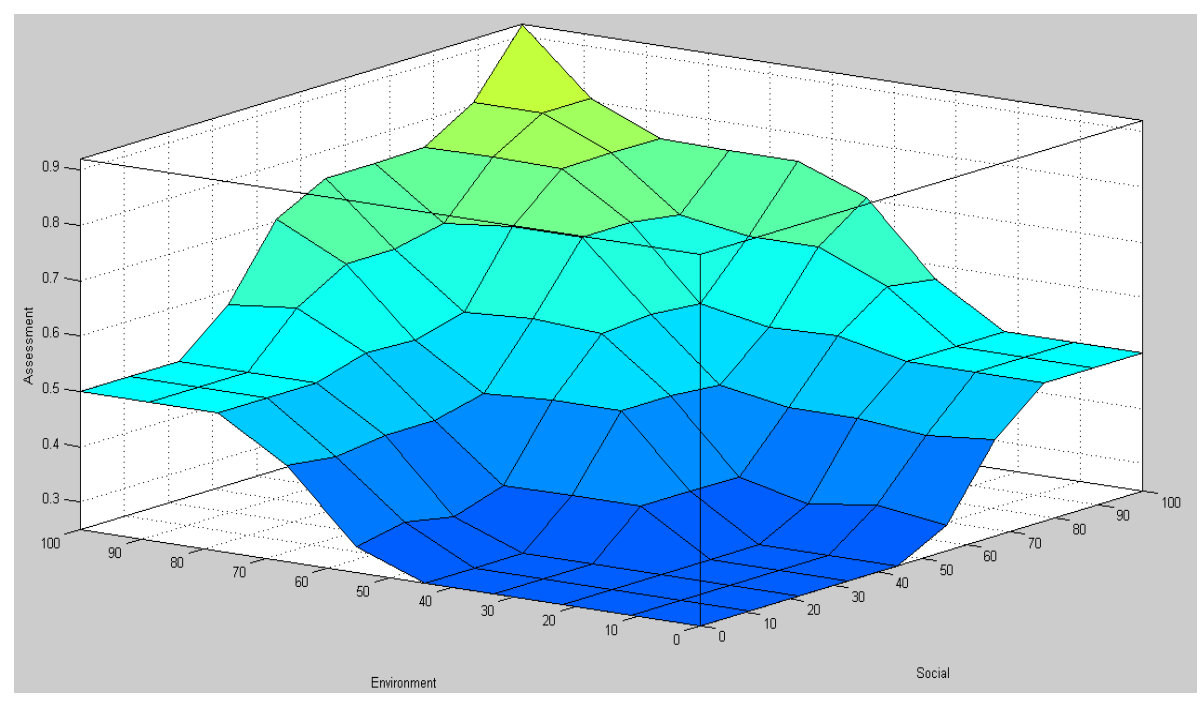

Figure 4: Fuzzy rules reasoning process surface

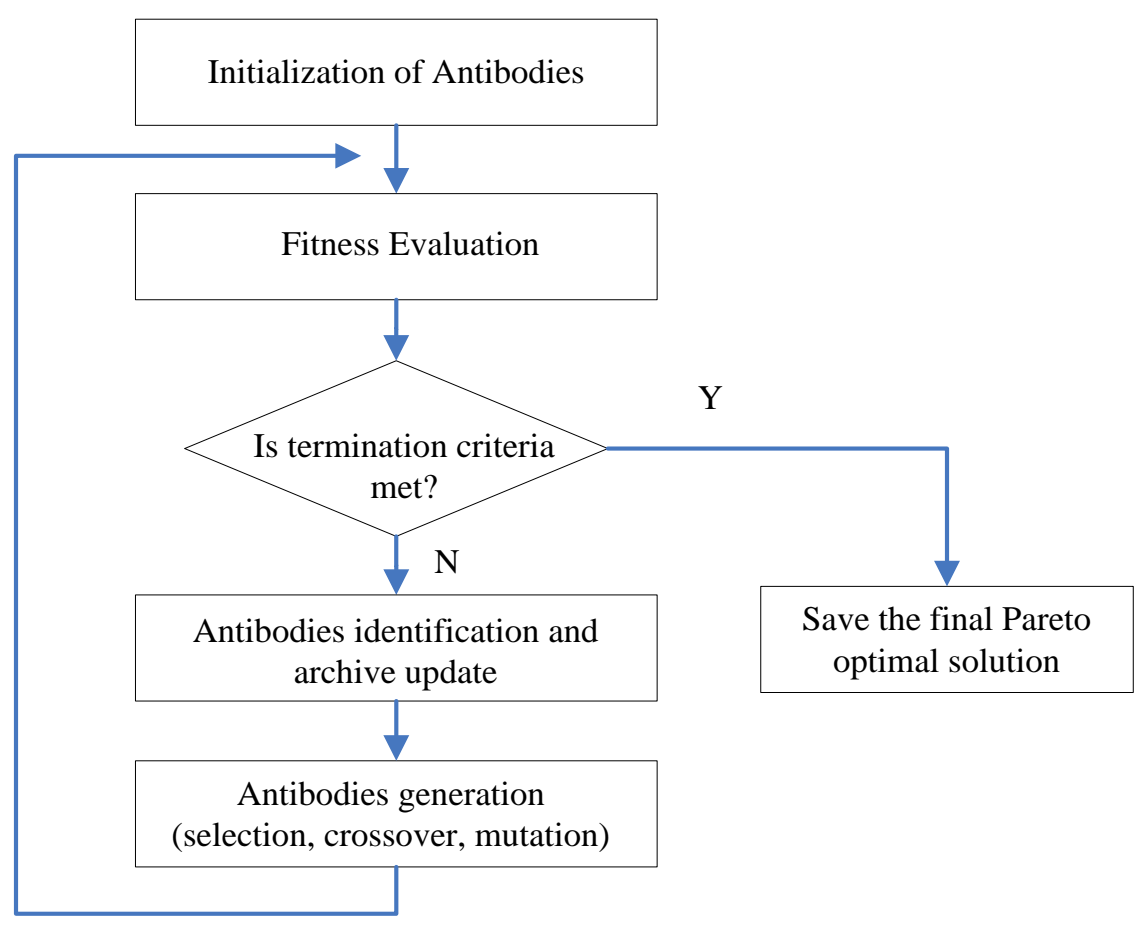

Figure 5: The flowchart of artificial immune optimization algorithm 


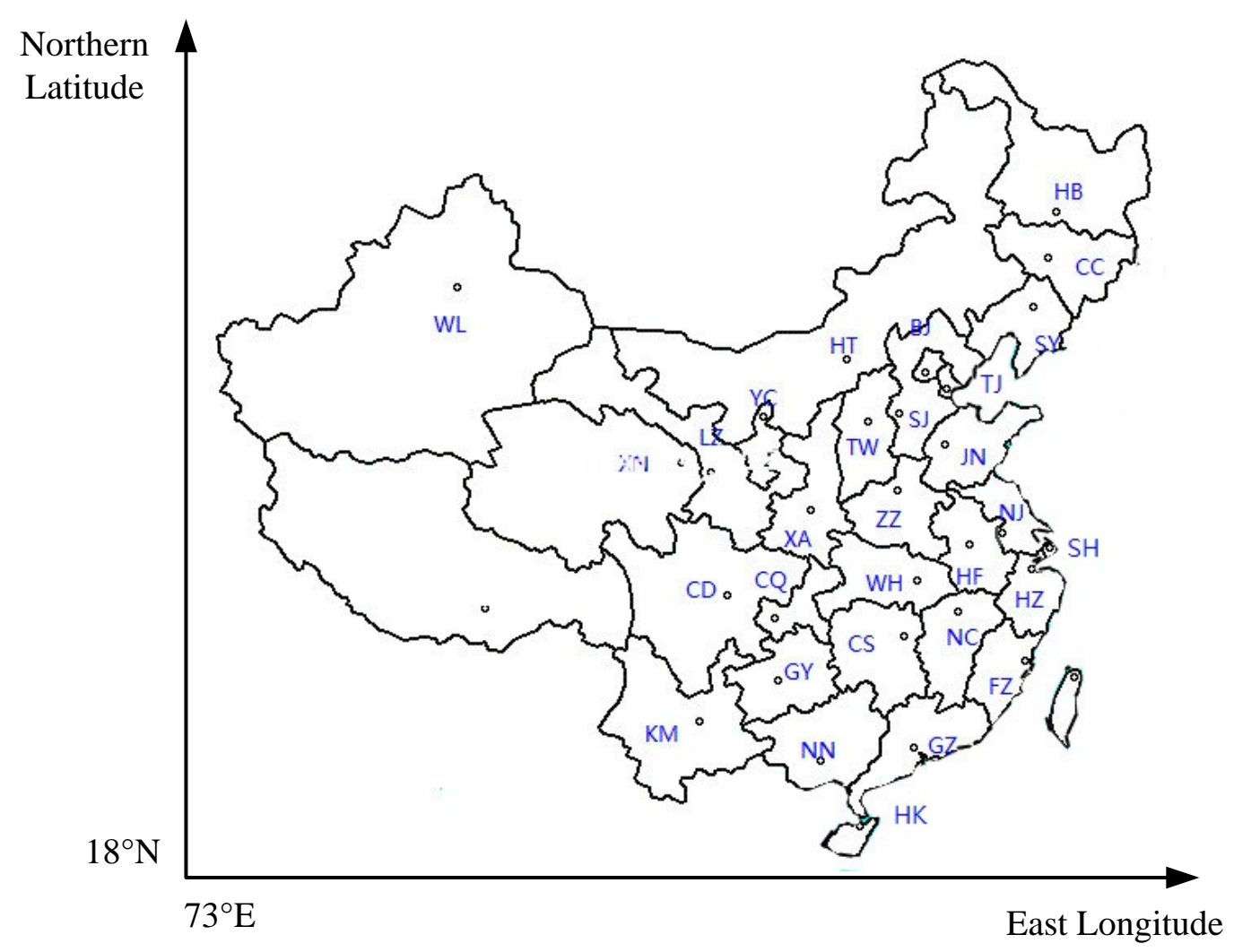

Figure 6: The relative location of thirty potential reverse logistics centres for Company XYY

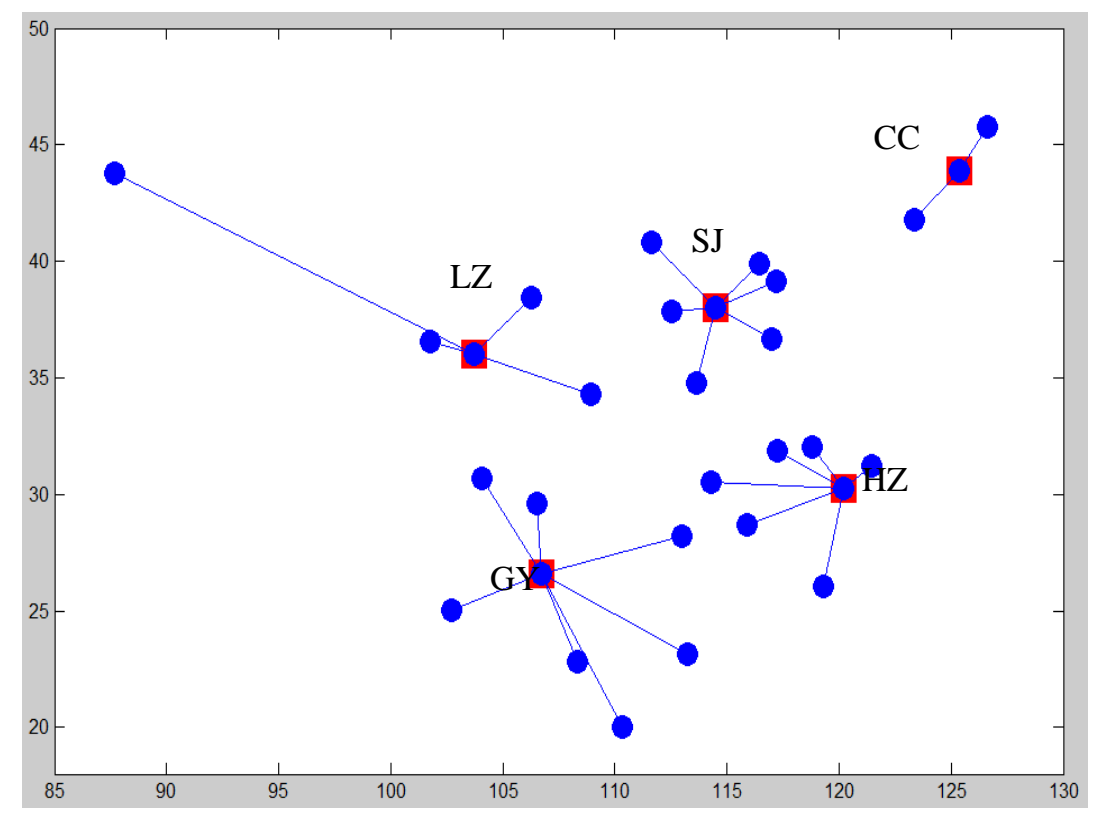

Figure 7: The optimal reverse logistics network and the selected reverse logistics centres 


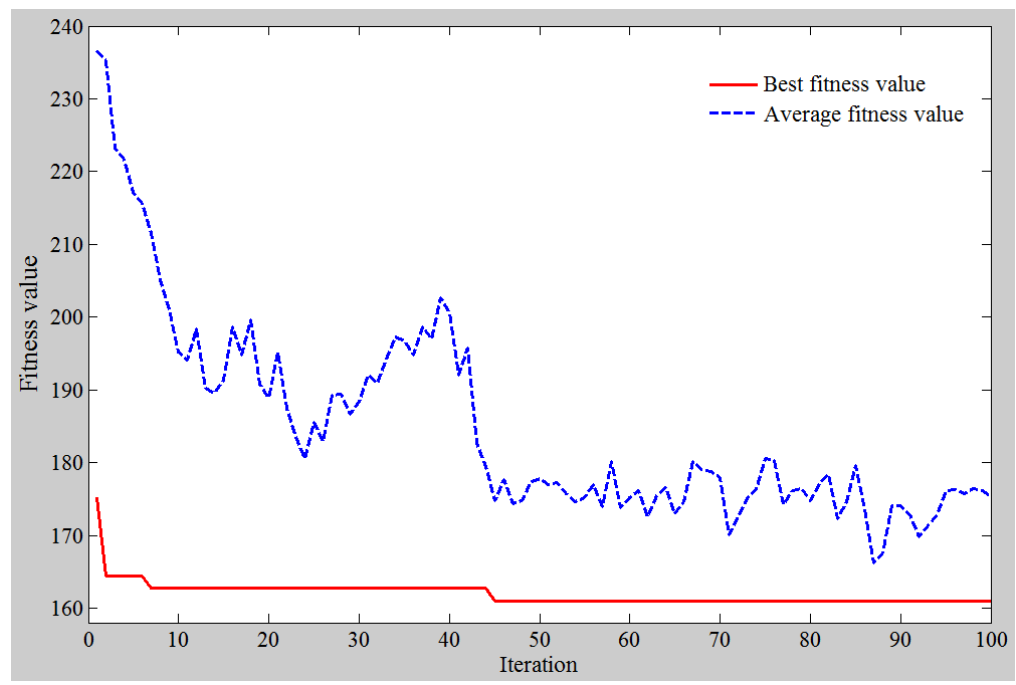

Figure 8: The artificial immune optimization process

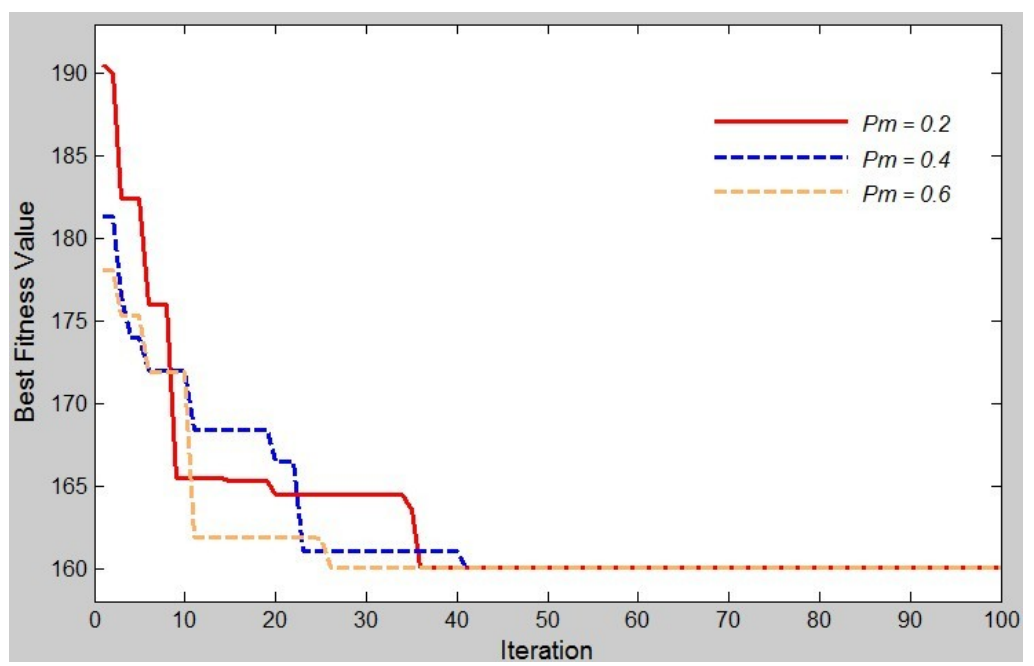

Figure 9a: The sensitivity analysis with respect of different rates of mutation

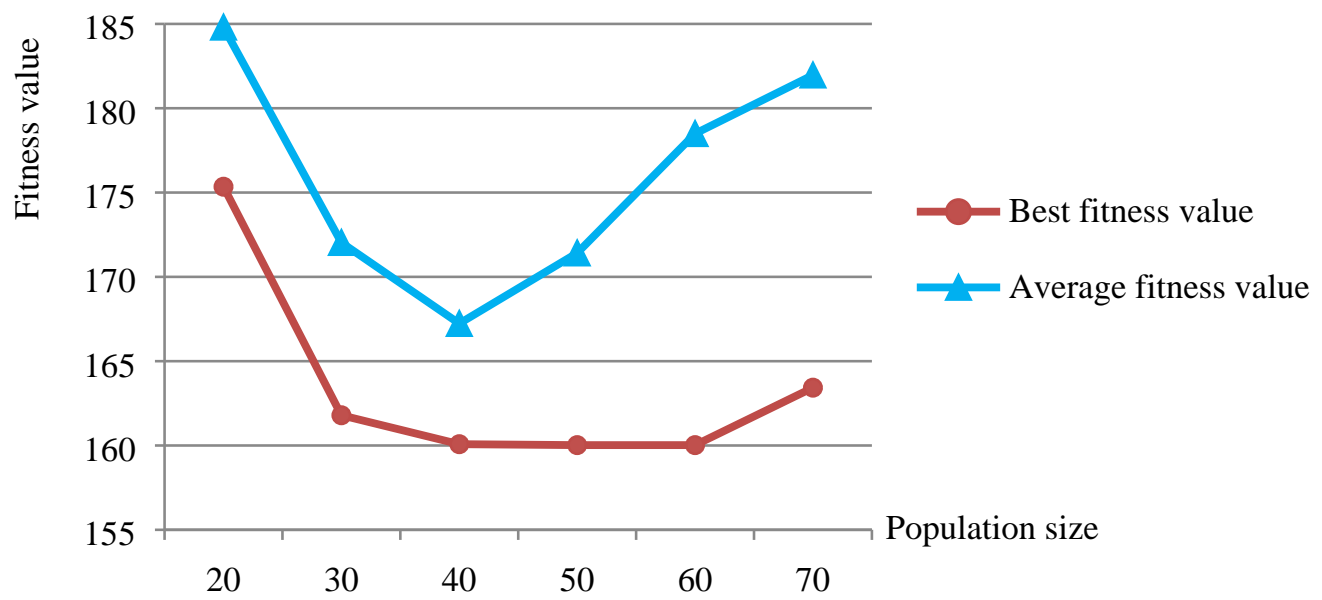

Figure 9b: The sensitivity analysis with respect of different population size 


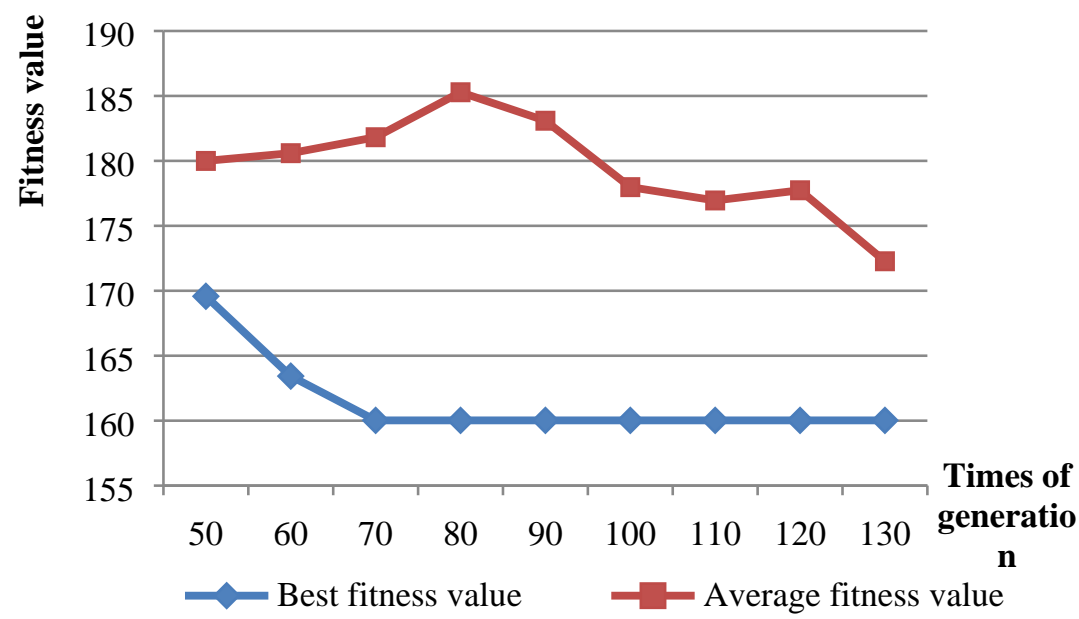

Figure 9c: The sensitivity analysis with respect of different times of generation

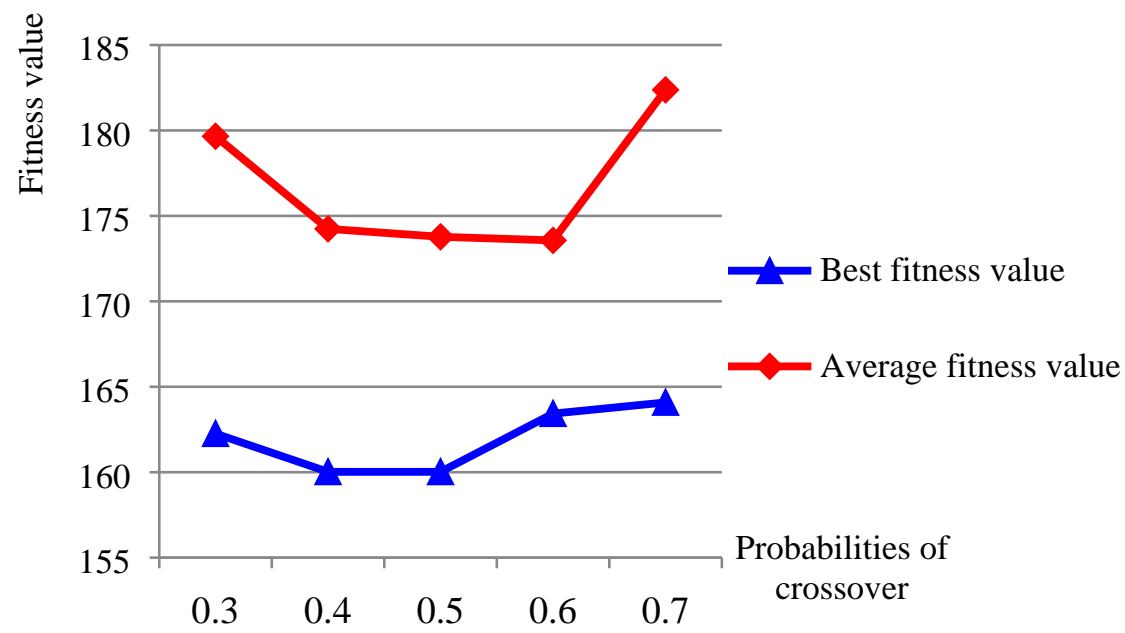

Figure 9d: The sensitivity analysis with respect of different probabilities of crossover

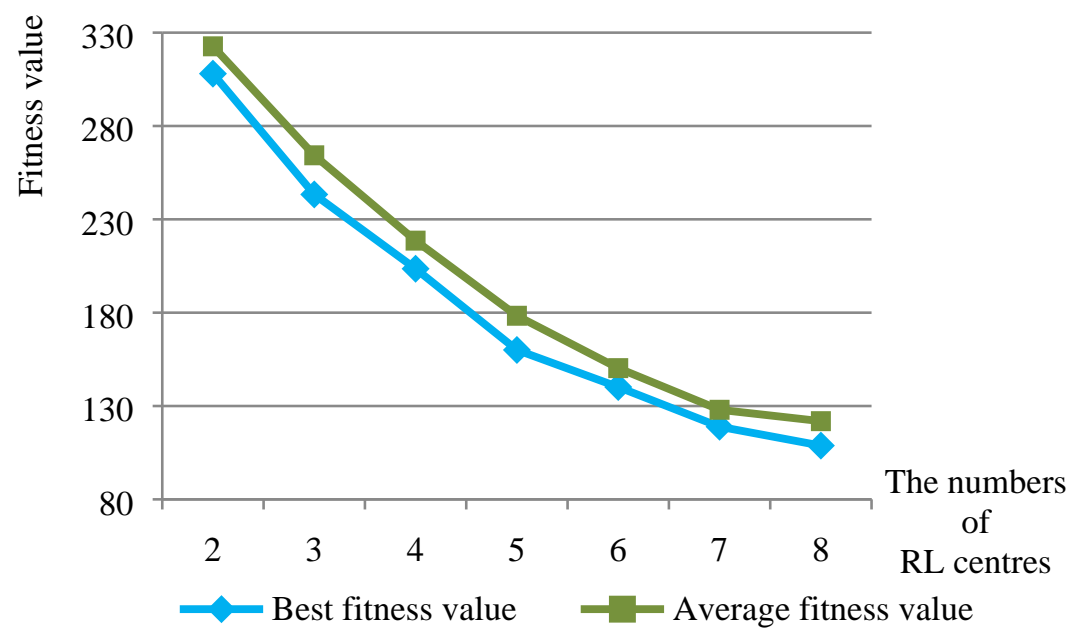

Figure 10a: The sensitivity analysis with respect of different numbers of RL centres 

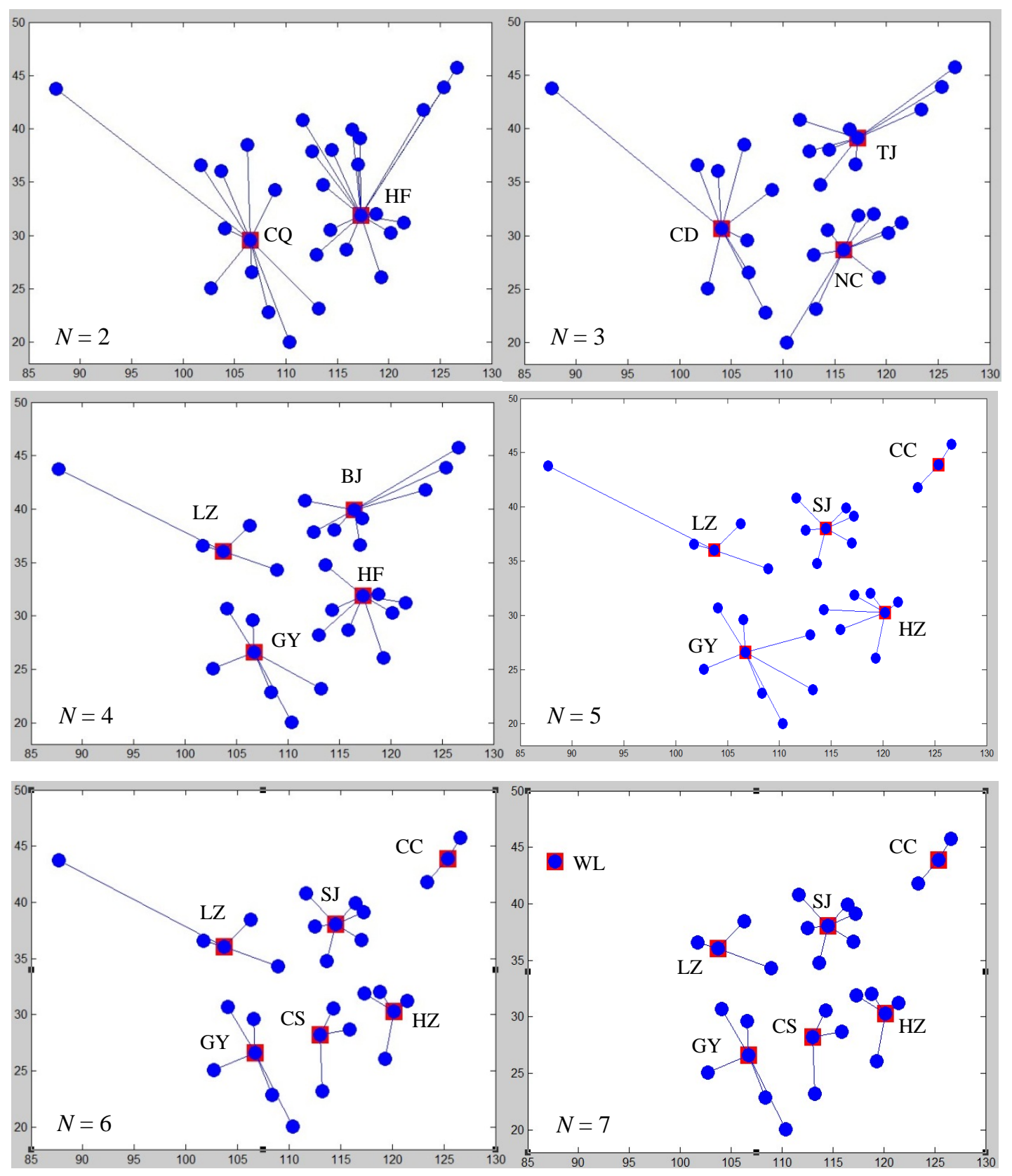

Figure 10b: The optimal RL network with respect of different numbers of RL centres 


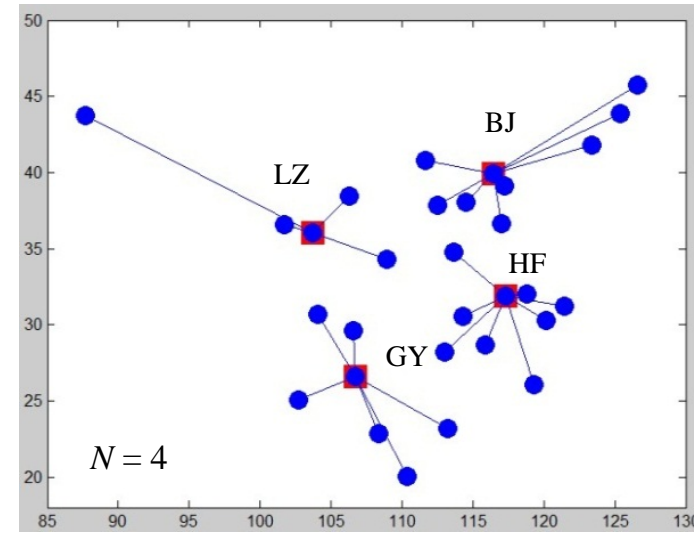

Comprehensive criteria considered

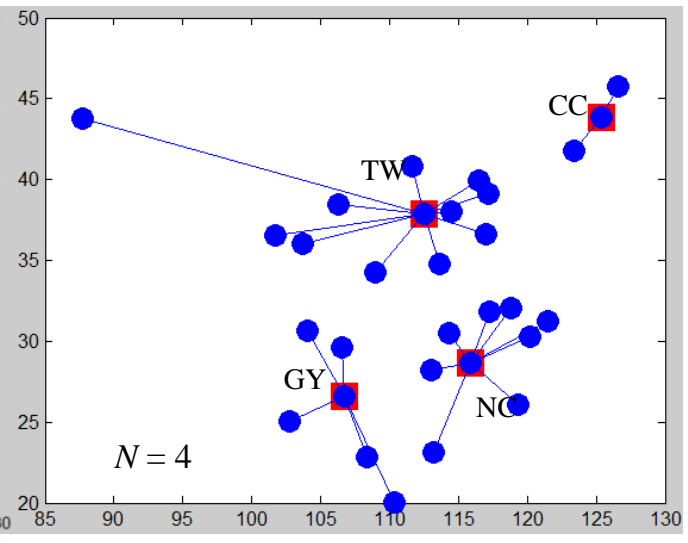

Only economic criteria considered

Figure 11: Comparisons of the optimal RL network with respect of different criteria set

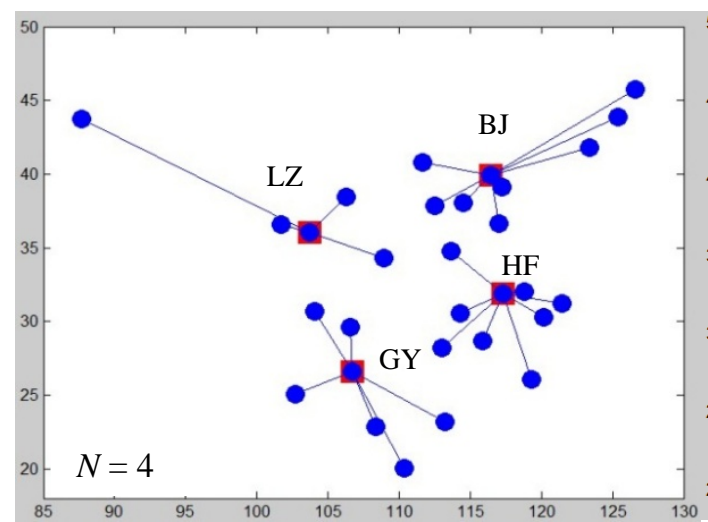

Comprehensive proposed model

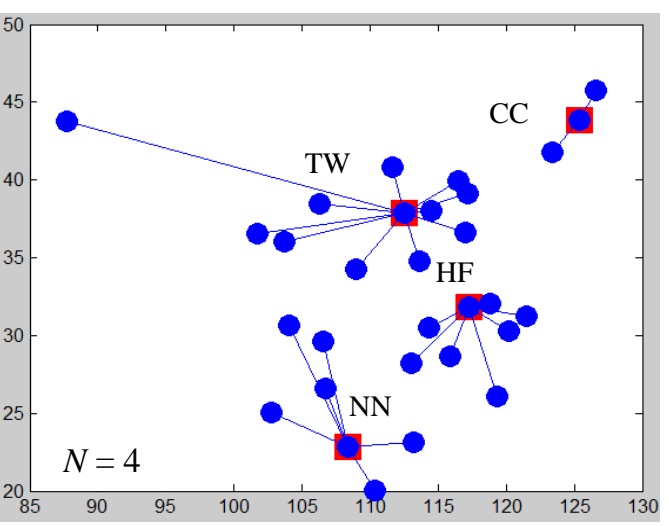

Only AIO sub-model employed

Figure 12: Comparisons of the optimal RL network with respect of if FST is employed 